\title{
PRINCIPIOS GENERALES DE DERECHO PENAL EN EL ESTATUTO DE ROMA DE LA CORTE PENAL INTERNACIONAL"
}

\author{
Kai Ambos
}

\section{INTRODUCCIÓN}

Más de cincuenta años después de los juicios de Nuremberg, la Comunidad internacional ha creado un Tribunal Penal Internacional (ICC) permanente. La dramática votación de Roma del día 17 de julio de 1998, que se prolongó hasta altas horas de la noche, aprobó por una abrumadora mayoría el Estatuto para la creación de un ICC por 120 votos a favor y 7 en contra, con 21 abstenciones ${ }^{1}$. Esta votación supuso un gran avance histórico y la conclusión inequívoca de la voluntad de frenar decididamente la impunidad de graves violaciones de Derechos Humanos.

Sin embargo, un examen más detenido del Estatuto de Roma nos lleva rápidamente de vuelta a complejos tecnicismos legales e insuficiencias, resultado del "espíritu de compromiso" presente en las negociaciones diplomáticas que tuvieron lugar en el edificio FAO de Roma. El Estatuto de Roma no es precisamente un depurado código de Derecho penal y procesal penal desde el punto de vista dogmático, ni podía serlo. Pero, es un intento de hacer concurrir los modelos de justicia criminal de más de 150 Estados dentro de un sistema legal más o menos aceptable para la mayoría de las delegaciones presentes en Roma. Esto se puede afirmar de todo el Estatuto, pero en especial de la Parte III, titulada "Principios Generales". Para los penalistas, la Parte General, es el centro de reflexiones dogmáticas y el punto de partida de todo modelo de justicia criminal. De momento, lo anterior está experimentando una aceptación cada

\footnotetext{
* Originalmente publicado en Criminal Law Forum 10 (1999), pp. 1-32. Traducción del inglés de Fernando del *. Cacho (C.E.U. San Pablo), revisión y actualización del autor.

Referente científico del Instituto Max-Planck de Derecho penal extranjero e internacional; asistente científico de la Universidad de Freiburg. Doctor por la Universidad de Munich (1992). Miembro de la delegación alemana de la Conferencia Diplomática de Roma. Este artículo expresa únicamente la opinión personal del autor.

${ }^{1}$ Rome Statute of the International Criminal Court, aprobado por the "United Nations Diplomatic Conference of Plenipotentiaries on the Establishment of an International Criminal Court" de 17 de julio de 1998, U.N. Doc. A/CONF,183/9 (1998) http://www.un.org/icc. Véase para una visión general AMBOS, "Sobre el fundamento juridico de la Corte penal internacional", Revista de Derecho Penal y Criminologia (Universidad Nacional de Educación a Distancia. Facultad de Derecho), 2nda Epoca. No. 5 (Enero 2000), pp. 127-169. - En este momento (11 de mayo de 2000) 10 Estados han ratificado el Estatuto y 96 lo han firmado <http://www.igc.org/icc/>.
} 
vez mayor en los llamados países del Common Law desde que recientes trabajos han tomado más en serio las consideraciones dogmáticas².

El presente trabajo tiene un objetivo limitado, que consiste en describir y analizar críticamente los principios generales del Estatuto de Roma (artículos 22 a 33). Los antecedentes de estas previsiones legales ya han sido tratados en otro lugar ${ }^{3}$. El análisis puede dividirse en tres partes. Primero, es necesario tratar los principios generales en sentido estricto. Complementando los principios de "nullum crimen y nulla poena" (artículos 22 a 24) se incluyen algunas previsiones en la Parte II del Estatuto ("Jurisdiction, Admissibility and Applicable Law"): el principio "ne bis in idem" (artículo 20) y el de ley aplicable (artículo 21). En segundo lugar, se encuentran las normas que prevén la responsabilidad penal individual (artículos 25, 28, 30), que se pueden a su vez dividir en elementos objetivos (actus reus) y elementos subjetivos de responsabilidad criminal (mens rea). La tercera categoría, incluye argumentos defensivos (defences) y en especial fundamentos sustantivos de exclusión de responsabilidad criminal (artículos 26, 27, 29, y 31 a 33).

Ciertamente, se podría hablar de una "doble estructura" siguiendo la tradicional distinción delito ("offence") - causa de exclusión de la responsabilidad ("defence"). En este caso, los principios en sentido estricto serían considerados también como "defences". Sin embargo, dado que el concepto de "defence" incluye demasiadas doctrinas legales diferentes ${ }^{4}$, parece más convincente limitarlo a los defensas procesales y a las causas materiales de exclusión de la responsabilidad criminal. Esta posición está acorde con la decisión de la Conferencia de Roma de no utilizar el término "defences" y sustituirlo por el de "circunstancias eximentes de responsabilidad penal" ("grounds for excluding criminal responsibility").

\section{PRINCIPIOS GENERALES EN SENTIDO ESTRICTO}

Los principios generales en sentido amplio abarcan todos los principios y reglas comprendidos en la Parte General; es decir, que además de los principios stricto sensu, también comprenden las reglas específicas de imputación. El Estatuto de Roma no hace esta distinción, pero sitúa algunos principios en sentido estricto al comienzo de los principios generales y otros dos en la Segunda Parte. Esta singular disposición surgió

\footnotetext{
${ }^{2}$ Véase en especial FLETCHER George, Rethinking Criminal Law (1978); FLETCHER George, Basic concepts of Criminal Law (1998); ROBINSON Paul, Fundamentals of Criminal Law (1988); ASHWORTH Andrew, Principles of Criminal Law (1999, $3^{2}$ Edición). Para un acercamiento estructural ver: ROBINSON Paul, Structure and Function in Criminal Law (1997).

${ }^{3}$ Véase SCHABAS William A., "General principles of Criminal Law in the ICC Statute, European Journal of Crime", Criminal Law and Criminal Justice (Eur.J.Crime Cr.L.Cr.J.) 6 (1998), pp. 400 y sgs.

${ }^{4}$ Véase ROBINSON Paul (1997), supra nota 2, pp. 11-12.
} 
durante las deliberaciones del Comité Preparatorio (PrepCom), sin que fuera modificada en Roma. ${ }^{5}$

El artículo 21 establece una jerarquía para el derecho aplicable: en primer lugar, deben emplearse el Estatuto, los elementos del delito y las normas sobre procedimiento y prueba ${ }^{6}$; en segundo lugar, los Tratados y los principios y reglas de Derecho Internacional; si lo anterior no fuera posible, serían de aplicación los principios generales de las leyes nacionales de los Estados con jurisdicción sobre los delitos, siempre y cuando sean compatibles con la ley internacional. Así, el Tribunal puede ir de una fuente a otra, hasta que encuentre la ley aplicable. En la práctica, tendrá que recurrir con frecuencia a los principios generales de la ley nacional en cuanto a que la ley internacional penal no prevé reglas en muchas áreas, en especial en relación con la Parte General.

La defensa puede invocar el principio ne bis in idem (artículo 20) ${ }^{7}$ ante cualquier Tribunal nacional o ante el ICC, cuando haya sentencia condenatoria o absolutoria del ICC por hechos que constituyen delitos comprendidos en la jurisdicción del ICC (artículo 20 (1), (2) ), es decir genocidio, delitos contra la Humanidad, crímenes de guerra y agresión (artículos 5-8). Excepcionalmente, sin embargo, una persona puede ser juzgada ante el ICC si un Tribunal nacional no se ha conducido de modo independiente o imparcial (artículo 20.3). Esta excepción se sigue de la regla de complementariedad (artículo 17). Por consiguiente, un juicio ante el ICC sólo es admisible si el Estado en cuestión no quiere o no puede acusar a una determinada persona. El artículo 20.3 contempla esencialmente los principios del artículo 17.2 (a) y (c) que permite al ICC el ejercicio de jurisdicción, incluso cuando los tribunales nacionales hayan juzgado o estén juzgando el mismo caso. En consecuencia, lo criticable del artículo 20 (3) se halla en la imprecisión de los criterios utilizados conforme al principio de complementariedad ${ }^{8}$.

El principio nullum crimen (sine lege scripta, praevia, certa et stricta) está explícitamente contemplado en sus cuatro diferentes formas ${ }^{9}$ (artículos 22, 24): una persona sólo puede ser castigada por una acción que estuviera prevista en el Estatuto al

\footnotetext{
${ }^{5}$ Draft Statute for the International Criminal Court, U.N. Doc. A/CONF.183/2/Add.1 (1998), art. 18-22.

${ }^{6}$ The Elements of Crimes and the Rules of Procedure and Evidence deben adoptarse más tarde por la Asamblea de Estados Parte, de conformidad con los artículos 9 y 51 respectivamente y con base en las reuniones de la Preparatory Commission que terminará su trabajo a finales de 2000

${ }^{7}$ WISE Edward, "General Principles of Criminal Law", en: SADAT-WEXLER (ed.), Model-Draft-Statute for the ICC based on the Preparatory Committee's Text to the Diplomatic Conference, Toulouse 1998, pp. 61-63.

${ }^{8}$ Véase por ejemplo ZIMMERMANN Andreas, "Die Schaffung eines ständigen internationalen Strafgerichtshofs". Zeitschrift für ausländisches öffentliches Recht und Völkerrecht 58 (1998) 47, 97-99.

${ }^{9}$ ROXIN Claus, Strafrecht-Allgemeiner Teil, tomo I, $3^{\text {era }}$ edic. 1997, págs. 97-99.
} 
tiempo de su comisión (lex scripta), que fuera cometida tras su entrada en vigor (lex praevia), que estuviera definida con suficiente claridad (lex certa) y que no fuera ampliable por analogía (lex stricta). Los últimos principios de ley cierta y de prohibición de la analogía, tienen por consecuencia que las ambigüedades han de ser resueltas en favor del inculpado. Además, los principios de ley escrita ("statute law")y de no retroactividad (lex praevia) ${ }^{10}$, dan al inculpado el derecho de ampararse en la ley en vigor al tiempo de la comisión. En caso de cambio de ley, antes de dictar sentencia, se ha de aplicar la que sea más favorable al reo.

Esta aparente estricta comprensión del principio nullum crimen, en especial del principio de no retroactividad, encuentra un sólido fundamento en Derecho penal comparado ${ }^{11}$ y se halla también reconocido en Derecho internacional ${ }^{12}$. Sin embargo, desde Nuremberg el principio ha sido interpretado de forma más liberal ${ }^{13}$. El Tribunal internacional militar rechazó el argumento de la defensa por el que la acusación de los principales crímenes de guerra era una acusación ex post facto, vulnerando, por tanto, el principio nullum poena sine lege praevia ( $y$ scripta), en cuanto que la agresión no era delito en el momento de su comisión por los nazis. El Tribunal de Nuremberg no siguió esta interpretación positivista del principio y se inclinó por un "principio de justicia":

"Afirmar que es injusto castigar a aquellos que desafiando Tratados y garantías han atacado Estados vecinos sin advertencia alguna, es obviamente falso, pues, en tales circunstancias el agresor debe saber que está haciéndolo mal, y no sólo no sería injusto castigarle, sino que, se haría injusticia permitiendo su equivocación con la impunidad"14.

\footnotetext{
${ }^{10}$ Véase también sobre jurisdicción "ratione temporis", art. 11: "1. 1. La Corte tendrá competencia únicamente respecto de crímenes cometidos después de la entrada en vigor del presente Estatuto."

${ }^{11}$ ROXIN, supra nota 9, en págs. 99 a 101; FLETCHER (1998), supra nota 2, pág. 207; CATENACCI Mauro, "Nullum crimen sine lege", en: LATTANZI Flavia (ed). The International Criminal Court, Comments on the Draft Statute, 1998, págs. 159-170.

12 Pacto Internacional de Derechos Civiles y Politicos, 999 U.N.T.S. 171, en vigor el 23 de marzo de 1976, artículo 15; Convención Europea de Derechos Humanos, 213 U.N.T.S. 221, en vigor el 3 de septiembre de 1953, artículo 7; Convención Americana de Derechos Humanos, 1144 U.N.T.S. 123, en vigor el 18 de julio de 1978, artículo 9; Universal Declaración Universal de Derechos Humanos, G.A. Res. 217 A (III), U.N. Doc. A/810 (1948), artículo 11 (2); Carta Africana de Derechos Humanos y de Pueblos, O.A.U. Doc. CAB $/ \mathrm{LEG} / 67 / 3 \mathrm{rev}$, 5, en vigor el 21 de octubre de 1986, artículo 7 (2): Convención de Ginebra de 12 de agosto, 1949 relativa al tratamiento de prisioneros de guerra, 75 U.N.T.S. 135, en vigor el 21 de octubre de 1950, artículo 99; Convención de Ginebra de 12 de agosto, 1949 en relación a la protección de civiles, 75 U.N.T.S. 135, en vigor el 21 de octubre de 1950, artículos 64, 67; Protocol Aditional I to the 1949 Convención de Ginebra relativa a la Protección de Víctimas de Conflictos Internacionales Armados, 1125 U.N.T.S 3, en vigor el 7 de diciembre de 1978, artículo 74 (4) (c); Protocol Aditional II 1949 Convención de Ginebra relativa a la Protección de Victimas de Conflictos Armados.

13 AMBOS Kai, "Nuremberg revisited. Das Bundesverfassungsgericht, Das Völkerstrafrecht und das Ruckwirkungsverbot", Strafverteidiger 1997, 39-43.

${ }^{14}$ France et al. v. Göring et al., Trial of the major war criminals before the International Military Tribunal tomo 23 (1946), p. 444
} 
Esta idea presidió los esfuerzos codificadores de Naciones Unidas que siguieron a Nuremberg. Mientras Nuremberg ${ }^{15}$ y el Código de $1954^{16}$ no se pronunciaron sobre tan delicado extremo, los Códigos de 1991 y 1996, sin embargo, siguieron básicamente el planteamiento del Tribunal internacional militar de 1946. De hecho, el enviado especial de la Comisión Internacional de Derecho (International Law Commission-ILC), Doudou Thiam, dejó buena constancia en su cuarto informe de que "la palabra "ley" (en el principio nullum crimen sine lege), debe ser entendida en su más amplio sentido, incluyendo no sólo la ley, sino también la costumbre y los principios generales del Derecho ${ }^{17}$ En consecuencia, la codificación de la ILC del principio de no retroactividad mantiene $e$ incluso hace hincapié en la posibilidad de una acusación "en base a diferentes criterios legales"; por ejemplo, una acusación no sólo basada en el Código penal, sino también en acuerdos y costumbres de Derecho internacional ${ }^{18}$. Por tanto, el artículo 10 (2) del Proyecto de Código de $1991^{19}$ y el artículo 13 (2) asimismo del Proyecto de $1996^{20}$ adoptan, esencialmente, la famosa cláusula de Nuremberg que se encuentra en el artículo 15 (2) del Pacto Internacional de Derechos Civiles y Políticos y demás acuerdos de Derechos Humanos ${ }^{21}$. La única diferencia sustancial radica en que la mayoría de la ILC rechazó la referencia a "los principios generales de la ley" como demasiado imprecisos, prefiriéndose la ley nacional o internacional para fundamentar la acusación ${ }^{22}$. La ley de Roma confirma la histórica discusión sobre el alcance y límites del principio nullum crimen, afirmando que el reconocimiento del principio "no afectará la caracterización de ninguna conducta como delictiva bajo la ley internacional independientemente de este Estatuto" (artículo 22 (3), enfatizado).

15 "Principles of International Law recognized in the Charter of the Nuremberg Tribunal and in the Judgment of the Tribunal", Yearbook ILC 1950, tomo II, págs. 374-378

${ }^{16}$ Draft Code of Offences Against the Peace and Security of Manking, Yearbook ILC 1954, tomo II, págs. 151-152 (también Yearbook ILC 1983, tomo I, pág. 4; Yearbook ILC 1953, tomo II, pág. 11; Yearbook ILC 1984, tomo I, págs. 4-5; Yearbook ILC 1984, tomo II, págs. 2, 8).

17 THIAM Doudou, Fourth Report on the Draft Code Offences against the Peace and Security of Mankind, Yearbook ILC 1986, tomo II, para. 163

${ }^{18}$ Véase para el Draft Code de 1991: Yearbook ILC 1988, tomo II, pág. 70; para el Draft Code de 1996: "Report of the ILC on the work of its forty-eighth session, Jun. 5-Aug, 26, 1996, "GAOR. 51th Session, Supp. No. 10 (A/51/10), en 72, para. 1,73 , para. 5 .

${ }^{19}$ Draft Code of Crimes Against the Peace and Security of Mankind, Yearbook ILC 1991, tomo II, págs. $94-97=$ "Draft Code 1991".

${ }^{20}$ Draft Code of Crimes Against the Peace and Security of Mankind, U.N. Doc. A/51/332, Report ILC (1996). supra nota 18; también 18 Hum. Rts L. J. 96 (1997) = "Draft Code 1996".

${ }^{21}$ Pacto Internacional de Derechos Civiles y Políticos, supra nota 12, artículo 15 (2): "Este artículo no supondrá prejuzgamiento alguno del juicio ni castigo por hechos u omisiones que al tiempo de su comisión fueran legalmente acordes con los principios generales de la ley reconocidos por la Comunidad de Naciones". Véase también: Declaración Universal de Derechos Humanos, supra nota 12, artículo 7 (2). Obsérvese, sin embargo, que el principio no se encuentra en las previsiones del nullum crimen de la Convención Americana de Derechos Humanos, supra nota 12, artículo 9, y el Carta Africana de Derechos Humanos y de Pueblos, supra nota 12. artículo $8(2)$.

22 Supra nota 18 
Finalmente, el artículo 23 prevé un limitado principio nulla poena (sine lege scripta, praevia, certa y stricta), al declarar que el condenado sólo lo puede ser a penas establecidas en el Estatuto. Sin embargo, dada la naturaleza general de las penas previstas en el Estatuto - prisión superior a treinta años o cadena perpetua por un lado, y multa y confiscación por otro (artículos 77-80) - el principio nulla poena sólo se cumple parcialmente. Se puede afirmar que el artículo 77 y siguientes, si bien cumplen con las exigencias de ley escrita y con el principio de irretroactividad, no, sin embargo, con los criterios de lex certa y lex stricta de las penas comunes a la ley penal nacional, por cuanto, no especifican las distintas sanciones correspondientes a los delitos comprendidos en la jurisdicción del Tribunal (artículos 5-8). El Estatuto de Roma va más allá todavía que todos los anteriores documentos de Derecho penal internacional, al especificar penas para todo supuesto cumpliendo, por tanto las exigencias del principio nulla poena tal y como es entendido en la ley penal internacional ${ }^{23}$.

\section{RESPONSABILIDAD PENAL INDIVIDUAL (ARTÍCULOS 25, 28, 30)}

\section{Elementos objetivos de la responsabilidad penal individual (actus reus)}

Los conceptos básicos sobre responsabilidad penal individual se encuentran en el artículo 25 (3) (a), (b) y (c). ${ }^{24}$ El resto de la previsión reafirma lo obvio: reconociendo la responsabilidad penal individual (parágrafos 1,2 ) y la consiguiente validez de las reglas de la responsabilidad estatal (parágrafo 4$)^{25}$; bien establece determinadas formas de participación y/o extensión de la imputación: contribuir a la comisión o intento de comisión de un delito por un grupo, incitación al genocidio, tentativa (artículo 25 (3) (d), (e) y (f)). Así, un individuo es responsable por un delito comprendido en el Estatuto (artículos 5-8) si realiza, toma parte o intenta un delito de conformidad con los subparágrafos (a) a (f). Este amplio margen de responsabilidad se complementa con una regla específica sobre el mando y responsabilidad del superior (artículo 28). Considerándolos conjuntamente, los artículos 25 (3) y 28 contienen un complejo conjunto de reglas objetivas de autoría que pueden dividirse en reglas básicas de responsabilidad penal individual y en reglas de extensión de la imputación (que pueden o no ser caracterizadas como formas específicas de participación).

\footnotetext{
${ }^{23}$ Véase TRIFFTERER Otto, Dogmatische Untersuchungen zur Entwicklung des materiellen Völkerstrafrechts seit Nürnberg, 1966, pág. 139 (demostrando que una norma general sobre penas es suficiente).

${ }^{24}$ Sobre el art. 25 ver también el analísis de este autor, en: TRIFFTERER (ed.). Commentary on the Rome Statute, Baden-Baden 1999.

${ }^{25}$ Estas declaraciones son tan antiguas como la historia de la codificación: véase el Proyecto de Código de 1954 supra nota 16, artículo 1; Proyecto de Código de 1991, supra nota 19, artículos 3(1). Proyecto de Código de 1996 supra nota 20, artículos 2 (1), 4. Véase también Thomas Weigend, artículo 3: Proyecto de Código 1991113 (M.C. Bassiouni, ed. 1993).
} 
La responsabilidad penal de las personas jurídicas fue planteada por Francia ${ }^{26}$. La propuesta final, presentada por el grupo de trabajo ${ }^{27}$, se limitó a las sociedades privadas, excluyendo Estados y otras organizaciones públicas y no lucrativas. Pero, además, se relacionó con la responsabilidad penal individual de quienes siendo los principales miembros de una sociedad mercantil ocupan una posición de control, y cometen el delito actuando en nombre y con el explícito consenso de la misma, y en el decurso de sus actividades. A pesar de tan limitada responsabilidad, la propuesta fue rechazada básicamente por diversas y convincentes razones, La inclusión de responsabilidad colectiva, no es compatible con la jurisdicción del Tribunal, que se centra en los individuos. Aún más, el Tribunal se enfrentaría con graves y a la larga, insuperables problemas de prueba. En resumen, puede afirmarse que no hay todavía un reconocimiento universal de criterios comunes sobre responsabilidad de las personas jurídicas y de hecho no siempre se reconocen en la mayoría de los modelos penales ${ }^{28}$. En consecuencia, tal ausencia de responsabilidad penal en la mayoría de los Estados, hace inaplicable este concepto complementario.

\section{a) Reglas básicas de la responsabilidad penal individual}

En contraposición con los proyectos, el artículo 25 (3) (a), (b) y (c) parece distinguir entre la autoría del delito (subparágrafo a) y otras formas de participación (subparágrafos b y c).

aa) Formas de autoría

El subparágrafo (a) distingue claramente entre tres formas de autoría: directa o inmediata ("por sí solo"), co-autoría ("con otro") y autoría mediata ("por conducta de otro"). De este modo, la co-autoría no se comprende en el concepto de complicidad ("complicity"), sino que se reconoce como una forma autónoma de autoría. La redacción original (inglés) del proyecto del subparágrafo (a) ("commits... as an individual"), sin embargo, no es muy afortunada. En primer lugar, de esta manera la autoría directa se refiere a la comisión "individual" de un delito, lo cual es confuso, porque parece repetir únicamente el principio de responsabilidad individual y no muestra suficientemente la importancia de la propia conducta individual actuando por

${ }^{26}$ U.N. Doc. A/CONF. 183/C.1/L.3 (1998), articulo 23(5), (6). Véase también Wise, supra nota 7, en 42, Andrea Sereni, Individual criminal responsibility, en: Flavia Lattanzi (ed.), supra nota 11, págs. 145-6.

${ }^{27}$ U.N. Doc, A/Conf. 183/C.1/WGGP/L.5 (1998).

${ }^{28}$ Cf. Recientemente: A. ESER, B. HUBER, K. CORNILS (eds.), "Einzelveranwortung und Mitveranwortung im Strafrecht". European Colloquium on Individual, Participatory and Collective Responsability in Criminal Law, Freiburg i.Br. 1998. 
uno mismo o utilizando otra persona ${ }^{29}$. La versión francesa anterior ("... a titre individuel") y la versión española son más claras en este sentido.

En segundo lugar, el subparágrafo (a) tipifica la comisión "con otro" o "por conducta de otro" ("jointly with another or through another person") "sin consideración a si esa otra persona es criminalmente responsable", lo que no tiene sentido en cualquier caso. La autoría mediata presupone que, la persona que comete el delito, puede ser utilizada como un instrumento o herramienta ("Werkzeug") por el autor mediato que actúa como cerebro o "hombre detrás" ("Hintermann"). Normalmente, se trata de un agente inocente, no responsable del acto delictivo. La Common Law considera al autor mediato como "principal" ${ }^{130}$. Un ejemplo típico es el del agente individual que actúa erróneamente o que no es culpable por ser menor de edad o padecer una deficiencia mental. Así, como la autoría mediata implica que la persona utilizada ("el instrumento") no es penalmente responsable, el reconocimiento expreso en el Estatuto de este hecho deviene superfluo.

Por otro lado, la co-autoría se caracteriza por una división funcional de las acciones delictivas entre los diferentes coautores, que están normalmente interrelacionados por un plan común o acuerdo. Todo coautor realiza cierta tarea que contribuye a la comisión del delito y sin la cual, la comisión no sería posible. El plan común o acuerdo constituye la base de una recíproca o mutua comunidad de esfuerzos que hace a todo coautor responsable del delito en su integridad. Es casi impensable que uno de los coautores no sea criminalmente responsable. La referencia del Estatuto a "aquella otra persona", muestra una laguna en la comprensión del concepto de coautoría. En suma, esta referencia sitúa a la misma altura conceptos que son estructuralmente muy diferentes y que, por tanto, deberían ser tratados en diferentes parágrafos o secciones ${ }^{31}$.

bb) Otras formas de participación

Los subparágrafos (b) y (c) se refieren a otras formas de participación que en sí mismas, sin embargo, suponen diferentes grados de responsabilidad. El subparágrafo (b) se refiere a una persona que ordena, solicita o induce a la comisión o tentativa de delito. El subparágrafo (c) preceptúa cualquier otra forma de auxilio ("ayuda",

\footnotetext{
${ }^{29}$ Véase Model Penal Code (American Law Institute, 1985, hereinafter MPC), sec. 2.06 (1): "commited by his own conduct": Código penal español (Ley Orgánica 10/1995, de 23.11.1995, hereinafter CPesp), artículo 28: "por si solos": CP alemán (Strafgesetzbuch-StGB) § 25 (1): "selbst... begeht". En la ley penal francesa el "auteur mediat" no está codificado, pero si se reconoce excepcionalmente que el autor directo sea utilizado como un "simple instrumento" (cf. CZEPLUCH Anna Katherina, Täterschaft und Teilnahme im französischen Strafrecht. 1994, págs، 30-33).

${ }^{30}$ Véase comentarios al MPC, supra nota 28, pág. 2.06.

${ }^{31}$ Ibid.; también CPesp., artículo 28; StGB, $§ 25$ (1) y (2).
} 
encubrimiento o cualquier otra forma de asistencia ... incluyendo la provisión de medios) en la comisión o tentativa de delito "por el propósito de facilitarlo". Generalizando, la participación en el caso del subparágrafo (b), supone un grado mayor de responsabilidad que en el caso del subparágrafo (c).

De hecho, las formas de participación previstas en el subparágrafo (b), son muy diferentes. Quien ordena un delito no es un mero cómplice, sino realmente un autor mediato que se sirve de un subordinado para cometer el delito. En realidad, el mismo artículo 2 (1) (b) en el Proyecto de Código de 1996 intentó prever la responsabilidad criminal de oficiales que ordenaron a sus subordinados cometer crímenes ${ }^{32}$. En este sentido, la primera alternativa del subparágrafo (b) ("ordenar") complementa la responsabilidad contemplada en el artículo 28: en el último caso, el superior es responsable por omisión; en el supuesto de ordenarlo, lo será por comisión. Así, la primera alternativa del subparágrafo (b), pertenece a las formas de autoría previstas en el subparágrafo (a), tratándose de una forma de comisión "a través de otra persona".

Instigar a la comisión de un delito significa, entre otras cosas, ordenar, alentar, rogar o incitar a otra persona a realizar determinada conducta tipificada penalmente ${ }^{33}$. Inducir, significa básicamente influir en otra persona para que cometa un delito ${ }^{34}$. Inducir, es una especie de "paraguas" terminológico que comprendería la instigación, que a su vez, tiene un significado más preciso que la inducción. La inducción, es suficientemente amplia para comprender cualquier conducta que conduzca a otra persona a cometer un delito, incluyendo la instigación. De hecho, la versión francesa del Estatuto habla de "sollicite ou encourage" utilizando, por tanto, una forma de instigación que expresa el término inglés "induce".

El subparágrafo (c), como forma más débil de complicidad, comprende cualquier acto que contribuye a la comisión o a la tentativa de delito. ${ }^{35}$ La única limitación es de índole subjetiva en cuanto que el cómplice debe ayudar o facilitar de alguna forma la comisión del delito. Esta expresión se tomó del Código Modelo Americano ("Model Penal Code"). Aun cuando la necesidad de que concurra esta exigencia fue discutida en el American Law Institute, está claro que generalmente implica un requisito específico subjetivo más estricto que el mero conocimiento ${ }^{36}$. De

\footnotetext{
32 "Report of the ILC on the work of its forty-eighth session, Jun. 5-Aug. 26, 1996," supra nota 18, en 25 (para. 14).

${ }^{33}$ Black's Law Dictionary, $6^{\text {th }}$ ed. 1990 , pág. 1392; MPC, supra nota 28, s. 5.02 (1).

34 Black's Law Dictionary, $6^{\text {th }}$ ed. 1990 , pág. 774.

${ }^{35}$ Art. 25 (3) (c): "Con el propósito de facilitar la comisión de ese crimen, sea cómplice o encubridor o colabore de algún modo en la comisión o la tentativa de comisión del crimen, incluso suministrando los medios para su comisión."

${ }^{36} \mathrm{MPC}$, supra nota 28 , sec. 2.06 .
} 
otro lado, el subparágrafo (c) comprende toda forma de complicidad que no se encuentra contemplada por el subparágrafo (b). A primera vista surgen dos cuestiones. En primer lugar, debe ser suficiente y más razonable limitar la regla de complicidad a la inducción, al auxilio, y al encubrimiento. Estas formas de complicidad comprenden toda conducta que implica responsabilidad penal. En segundo lugar, y más importante, tiene que cuestionarse en qué consisten los requisitos mínimos de complicidad. El artículo 2 (3) (d) del ILC Proyecto de Código de 1996 exige que, tanto el auxilio como el encubrimiento sea "directo y substancial"; es decir, la contribución facilitaría la comisión de un delito de "forma significativa" ${ }^{137}$ El Tribunal Penal Internacional para la Antigua Yugoslavia ("International Criminal Tribunal for the Former YugoslaviaICTY") se refirió a estos criterios en el caso Tadic y sostuvo que el hecho en cuestión debía constituir una contribución directa y substancial para la comisión del delito ${ }^{38}$. "Substancial", significa que la contribución tiene su efecto en la comisión, o en otras palabras, que debe tener - de un modo u otro - una relación causal con el resultado ${ }^{39}$. Sin embargo, no exige necesariamente la presencia física en el lugar de los hechos. En Tadic, la Sala II ("Trial Chamber II") siguió un amplio concepto de complicidad basado en la teoría inglesa de la "concerned in the killing" 40 . De hecho, la Cámara no tomó el criterio "directo y substancial" muy en serio, en tanto incluyó en el concepto de ayuda y encubrimiento "todo acto de asistencia por medio de palabras o gestos que sirvan para alentar o apoyar" ${ }^{\prime 11}$. Así, tras el silencio del Estatuto de Roma, sigue la jurisprudencia internacional dejando abierta la cuestión. Queda por tanto (¡todavía!), para la futura jurisprudencia o para la doctrina, la tarea de desarrollar directrices más concretas que permitan construir los requisitos mínimos de complicidad. Hay que decir con todo, que en este momento no hay límites al concepto de responsabilidad del cómplice en el campo de los delitos internacionales.

El Estatuto de Roma no ofrece una solución para actos de complicidad posteriores a la comisión del delito. El ILC sólo incluye tales hechos en el concepto de complicidad si se basan en un plan de común acuerdo; de otra manera, la persona sería responsable por un delito distinto ("por favorecer el delito") ${ }^{42}$. EI ICTY, sin embargo,

\footnotetext{
${ }^{37}$ Report of the ILC on the work of its forty-eighth session. Jun. 5-Aug. 26, 1996, supra nota 18, en 24 (para. 10).

${ }^{36}$ Prosecutor V. Tadic (IT-94-1-T), mayo 7, 1997, paras. 674, 688-692<www.un.org/icty>.

${ }^{39}$ Ibid., para, 688

${ }^{40}$ Ibid., para. 687: "... no sólo que no se tiene que estar presente sino que la conexión entre el hecho que contribuye a la comisión y el hecho de comisión por si mismo pueden ser distantes en tiempo y en el espacio. Para la "concerned in the killing doctrine", véase: United Nations War Crimes Commission, Law Reports of Trials of War Criminals, Volumes I-XV, London 1947-1949, aqui tomo XV, pág. 49-51; también: Prosecutor V. Tadic, supra nota 37 , para. 691

${ }^{41}$ Prosecutor v. Tadic, supra nota 37, para 689.

${ }^{42}$ Yearbook... 1991, tomo II, p. 98; Yearbook... 1991, tomo I, p. 188, para.21 (Mr, Pawlak, chairman of the Drafting Committee). Véase también: Yearbook... 1990, tomo I, pp. 17, 23, 28, 48; Yearbook.,. 1990, tomo II, pp. 28 y siguientes. (paras, 28 y siguientes). Cf. También: MPC, supra nota 28, sec. 2.06; Christine Van den 
extiende la responsabilidad penal también a estos hechos, y siempre a "todos los que naturalmente resulten de la comisión del hecho en cuestión ${ }^{143}$.

Por supuesto, nadie puede ser único responsable por su contribución al delito sin tener en cuenta la responsabilidad de otros participantes. Aunque esto no se encuentre expresamente en el Estatuto, se puede inferir del principio de culpabilidad y del principio de responsabilidad penal individual. Esto implica que la responsabilidad de cada participante tiene que determinarse individualmente sobre la base de su contribución de hecho al delito en cuestión. Esto también excluye una forma de responsabilidad para actos de una tercera persona ("vicarious responsibility"). Por el contrario, el cómplice es responsable por su contribución al delito. Esta contribución determina el alcance de la imputación y de la culpa ${ }^{44}$.

\section{Extensiónes de la imputación}

a) Contribución al delito colectivo o su tentativa.

El subparágrafo (d) del artículo $25(3)^{45}$ significa la más limitada expansion del concepto de autoría, criminalizando "cualquier otra forma" que contribuya a la comisión o tentativa de delito por un grupo de personas actuando con un mismo fin. Exceptuando los requisitos generales subjetivos - a tratar después - tal contribución tiene que ser hecha "con el objetivo de alentar la actividad delictiva o el propósito criminal del grupo", suponiendo que tal actividad o propósito comprende la comisión de un delito. Esta formulación está basada en una Convención antiterrorista recientemente adoptada ${ }^{46}$ y representa un compromiso con las anteriores previsiones acerca de la "conspiración" ${ }^{147}$, que desde Nuremberg ha sido objeto de controversia ${ }^{48}$. El

Wyngaert. The Structure of the Draft Code and the General Part, in Commentaries on the ILC's 1991 Draft Code 55-56 (M.C. Bassiouni, ed., 1993); Weigend, supra nota 24, en 116-7.

${ }^{43}$ Prosecutor v. Tadic, supra nota 37, para 692 (enfatizado).

${ }^{44}$ Cf. WISE, supra nota 7, en 42.3; SERENI, supra nota 25, 139-146. Véase también: Draft Statute for the International Criminal Court, supra nota 5, artículo 23 (3): "La responsabilidad penal es individual y no puede ir más allá de la persona y bienes".

45 "(d) Contribuya de algún otro modo en la comisión o tentativa de comisión del crimen por un grupo de personas que tengan una finalidad común. La contribución deberá ser intencional y se hará:

i) Con el propósito de llevar a cabo la actividad o propósito delictivo del grupo, cuando una u otro entrañe la comisión de un crimen de la competencia de la Corte; o

ii) A sabiendas de que el grupo tiene la intención de cometer el crimen;"

${ }^{46}$ International Convention for the Suppression of Terrorist Bombings, U.N. Doc. A /RES/52/164 (1998), annex, art. $2(3)(c)$.

${ }^{47}$ Por ejemplo: Draft Statute for the International Criminal Court, supra nota 5, artículo 23 (7) (e) (ii).

${ }^{49}$ Véase por ejemplo, PELLA Vespasian, Memorandum, Yearbook ILC 1950, tomo II, pp. 278-362, 357; GRAVEN Jean, Les Crimes contre I'Humanit, Recueil des cours de I'Academie de Droit International 433-605, 502-503 (1950); Hans-Heinrich JESCHECK, Die internationale Genocidium-Konvention vom 9. Dezember 1948 und die 
ILC-Proyecto de Código de 1991, entiende que debe castigarse al individuo que "conspira para" la comisión de un delito, de donde convierte la conspiración en una forma de "participación en un plan común para la comisión de un delito contra la paz y la seguridad de la Humanidad"49. El Proyecto de Código de 1996 se extiende a una persona que "directamente participa en planear o conspirar para cometer tal delito que de hecho tiene lugar ${ }^{1150}$. De este modo, se limita la responsabilidad si se compara con las tradicionales previsiones sobre la conspiración por las que se exige una participación directa - ya referida anteriormente - y una efectiva comisión del delito. El Estatuto de Roma toma esta limitación más allá, eliminando totalmente el término conspiración y exigiendo al menos una contribución al intento colectivo de cometer un delito. Esto, de hecho, suprime el concepto de conspiración en favor de otra amplia forma de complicidad similar al auxilio y encubrimiento con el significado del subparágrafo (c) ${ }^{51}$. La única diferencia entre los subparágrafos (c) y (d) - a nivel objetivo - consiste en el objeto de la contribución: se trata en ambos casos de un delito (o de su tentativa), si bien en el caso del subparágrafo (c) no necesita planearse y realizarse por un grupo. Sin embargo, es difícil imaginar situaciones en las que las conductas punibles de conformidad con el subparágrafo (d) no estén ya contempladas por el subparágrafo (c). En otras palabras, el subparágrafo (d) resulta - a la luz de la amplia responsabilidad establecida en el subparágrafo (c) - sencillamente superfluo.

b) La incitación al genocidio

El Subparágrafo (e) del artículo 25 (3) tipifica penalmente la incitación directa y pública pero sólo en relación con el genocidio. Su paralelismo con el artículo III (c) de la Convención sobre el Genocidio de $1948^{52}$ provoca la misma crítica. Algunas delegaciones argumentaron que, la incitación como especial forma de complicidad en el

Lehre vom Völkerstrafrecht, "66 ZStW 193-217, 213 (1954); recientemente: RAYFUSE Rosemary, "The Draft Code of Crimes against the Peace and Security of Mankind: Eating Disonders at the International Law Commission", 8 Crim. L.F. 52 (1997). - Véase también el comunicado del delegado alemán KATHOLNIGG en la Conferencia Diplomática para la Adopción del Acuerdo sobre drogas de 1998 (United Nations Conference for the Adoption of a Convention against illicit Traffic in Narcotic Drugs and Psychotropic Suctances, Vienna, 1988, Official Records, tomo II, para. 52: "concepto desconocido en los modelos legales civiles". Sin embargo, se reconoció en un principio por el ILC Special Rapporteur Doudou Thiam (Yearbook ILC 1990, tomo II, p. 16, para. 66).

\footnotetext{
${ }^{49}$ Yearbook ILC 1991, tomo II, pág. 99 (comentario al artículo 3).

${ }^{50}$ Supra nota 20, artículo 2 (3) (e).

${ }^{51}$ De modo semejante, MPC, supra nota $28, \S 2.06$. que no tiene a la "conspiracy" como base de la responsabilidad si bien cuestiona el comportamiento del acusado como constitutivo de complicidad.

${ }^{52}$ Rafael LEMKIN, “Genocide as a Crime under International Law”, 41 Am. J. Int. L. 145 (1947);. KUNZ L Josef, "The United Nations Convention on Genocide". 43 Am. J. Int. L. 732, 738 (1949); JESCHECK Hans-Heinrich, supra nota 47, en 203 y siguientes. Recientemente salió el analísis profundo de GIL GIL Alicia, Derecho Penal Internacional, Madrid 1999. - Ver también la sentencia historica de la Bundesgerichtshof, en: Neue Zeitschrift für Strafrecht 1999, $396 \mathrm{ff}$. con comentario de AMBOS; ver también el comentario de GIL GIL, en: Revista de Derecho Penal y Criminología de la UNED, 2nda epoca, no. 4 (1999).
} 
delito de genocidio, no debería incluirse en la Parte General del Estatuto, sino en la previsión específica del delito de genocidio (artículo 6), para dejar claro así, que la misma no se reconoce para otros delitos. Este argumento es cuestionable, sin embargo, en cuanto que la incitación está contemplada bajo otras formas de complicidad, y en especial, en el caso del Estatuto de Roma, bajo la inducción como ha sido tratado más arriba. Normalmente la diferencia entre una forma ordinaria de complicidad - por ejemplo la instigación - y la incitación, se halla en el hecho de que la primera se encuentra dirigida especialmente a cierta persona o grupo de personas en particular mientras que la última se dirige al público en general. EI ILC hace - con razón referencia al uso de los medios de comunicación para promover la comisión del genocidio en Ruanda, en orden a justificar la inclusión de la incitación directa y pública como subparágrafo (f) del artículo 2 (3) del Proyecto de Código de 1996 ${ }^{53}$. "Directo", en este contexto, significa que una persona es especialmente acuciada a llevar a cabo de modo inmediato la acción criminal, de modo que, no es suficiente una vaga sugestión ${ }^{54}$. Así, la calificación de "directo" supone un concepto de incitación más estrecho que las formas normales de complicidad, como la instigación o la inducción. El çoncepto pierde su original sentido, que no es otro que la prevención de un incontrolable e irreversible peligro de comisión de ciertos delitos masa. Si un individuo insta a otro conocido suyo a llevar a cabo una acción criminal, tiene el mismo control sobre el actual autor que un instigador o cualquier otro cómplice. Aún más, el subparágrafo (e) contiene una diferencia mayor si se compara con las formas de complicidad de los subparágrafos (b), (c) y (d): la incitación en relación con el genocidio no exige la comisión o intento de comisión del delito, en este caso del genocidio. Así, el subparágrafo (e) rompe con la dependencia del acto de complicidad abandonando el principio de accesoriedad ("Akzessorietätsgrundsatz") que preside los parágrafos (b) a (d). Es punible el hecho de que alguien incite directa y públicamente a la comisión del genocidio, aun cuando dicho delito no se cometa de hecho ${ }^{55}$.

\footnotetext{
53 "Informe del ILC en su 40 sesión. Jun. 5-Aug. 26, 1996, supra nota 18, en 26-7 (para.16). Véase también sobre la importancia de la incitación en relación al genocidio en Ruanda: ICTR-Trial Chamber I, Prosecutor v. Jean Paul Akayesu. Case No. ICTR 96-4-T. Judgement. 2 September 1998, par. 672-5; Prosecutor v. Jean Kambanda. Case No. ICTR 97-223-S. Judgement and Sentence. 4 September 1998, par. 40 (count 3). Ambas decisiones disponibles en <www.ictr.org >.

${ }^{54}$ Informe ILC 1996, supra nota 18, en 26.

${ }^{55}$ Cf. WEIGEND, supra nota 24, en 115-116 (regarding the 1991 Draft Code, supra nota 19, artículo 2 (3) distinguiendo entre "soliciting" y "aiding" por un lado, e incitación y conspiración por otro).
} 


\section{c) Tentativa y desistimiento}

La tentativa se contempla en el parágrafo (f) del artículo $25(3)^{56}$. El concepto no se restringe a determinados delitos (como se propuso en la $\mathrm{ILC}^{57}$ ), pero generalmente se define como el "inicio de ejecución" de cierto delito por medio de una "acción sustancial". Esta definición es una combinación de derecho norteamericano y francés ${ }^{58}$, y se utilizó ya en el Proyecto de Código de 1991 (artículo 3 (3)) y en el Proyecto de Código de 1996 (artículo 2 (3) (g)). La cuestión consistió y todavía consiste en saber, de acuerdo con esta definición, cuándo comienza de hecho la tentativa. Está claro que los actos preparatorios no se incluyen en cuanto que no representan un "comienzo de ejecución". De hecho éste fue el único tema no controvertido en el ILC al discutir la tentativa ${ }^{59}$. No está claro, sin embargo, si el concepto alemán de inicio de tentativa por "dar principio directamente a la realización del tipo" ("unmittelbares Ansetzen zur Tatbestandsverwirklichung") se encuentra en el ámbito del artículo 25 (3) (f). A primera vista el concepto alemán parece diferir del "commencement of execution", en cuanto que para el primero, el autor sólo debe estar muy próximo a la ejecución del delito, pero no tiene que haberlo ejecutado en parte. Sin embargo, según el ILC ese "commencement of execution", indica que el individuo ha desarrollado un acto que constituye un paso decisivo para la consecución del delito ${ }^{60}$. En consecuencia, no se exige que el delito en cuestión sea ejecutado en parte, y así la persona en cuestión, no necesita haber realizado uno o más elementos del delito. La versión francesa del Estatuto también se refiere a "un comienzo de ejecución" empleando la terminología del artículo 121-5 del Código Penal. En Francia, el concepto siempre se ha entendido en un amplio sentido, comprendiendo "todo acto que tiende directamente al delito" ${ }^{11}$. Esto se corresponde con la definición de la ILC y significa que, siendo prácticos, no hay diferencia entre "comienzo de ejecución" y "dar principio directamente a la realización del tipo". Aún más, la última definición supone una

\footnotetext{
56 "(f) Intente cometer ese crimen mediante actos que supongan un paso importante para su ejecución, aunque el crimen no se consume debido a circunstancias ajenas a su voluntad. Sin embargo, quien desista de la comisión del crimen o impida de otra forma que se consuma no podrá ser penado de conformidad con el presente Estatuto por la tentativa si renunciare integra y voluntariamente al propósito delictivo."

${ }^{57}$ EI ILC no pudo alcanzar el consenso para aprobar una lista de delitos que pudieran ser intentados en cuanto que muchos miembros y gobiernos consideraron que el intento sólo era posible en el caso de crimenes de guerra o de crímenes contra la Humanidad (Yearbook ILC 1986, tomo II part 2). p. 49, para. 128; Yearbook ILC 1990, tomo I, pp. 6, 21, 70; Yearbook ILC 1990, tomo I, p. 188; Yearbook ILDC 1991, tomo II (Part. 2), p. 99; Yearbook ILC 1994, tomo II (Part 2), pp. 77, 85 (para. 196); Yearbook ILC 1994, tomo I, pp. 110, 121, 145 (para. 10).

${ }^{58}$ Código penal francés, artículo 121-5: "commencement d'execution"; MPC, supra nota 28, o 5.01 (1) (c): "substantial step". Cf. WISE, supra nota 7, en 44.

${ }^{59}$ Yearbook ILC 1986, tomo II. p. 49 (para. 129).

${ }^{60}$ Informe del ILC en su 40 sesión, Jun. 5-Aug. 26, 1996, "supra nota 18, p. 27 (para. 17).

${ }^{61}$ Cf. Herv PELLETIER/Jean PERFETTI, Code Penal 1997-1998, 10 th ed. 1997, pág. 20.
} 
exigencia de responsabilidad por el intento de comisión delictiva por cuanto - al menos teóricamente - resulta claramente diferenciado de los delitos consumados.

La posibilidad del desistimiento no se previó para el proyecto de Código penal de la ILC ${ }^{62}$, pero se tuvo en cuenta en el PrepCom ${ }^{63}$. Se incluyó en el Estatuto de Roma en el último minuto tras la propuesta japonesa. La formulación está basada en la Parte General del actualizado proyecto de Siracusa ${ }^{64}$ y recompensa a la persona que - en términos objetivos - desiste de cometer el delito o de cualquier otro modo impide su comisión y en términos subjetivos - abandona completa y voluntariamente el propósito de delinquir. El requisito esencial de exención en caso de desistimiento, es que el autor abandone voluntariamente la ejecución o impida la consumación del hecho. Esto implica que ha de abandonarse de un modo u otro el propósito de delinquir. Resulta superfluo hacer mención más específica sobre esta materia.

d) Responsabilidad del superior

El tantas veces reconocido principio de responsabilidad de mando se encuentra previsto en el artículo $28^{65}$. Esta previsión legal distingue entre la responsabilidad de militares (parágrafo 1) y de superiores civiles (parágrafo 2) ${ }^{66}$. Las codificaciones previas

62 De modo similar los comentadores franceses consideran el desistimiento como parte de la definición de intento (cf. Stefani/Levasseur/Bouloc, Droit penal general, 16 ed, 1997, pág. 203).

${ }^{63}$ Decisiones del Comité Preparatorio en sus sésiones de 11 a 21 de Febrero de 1997, U.N. Doc. A/AC. 249/1997/L.9/Rev.1, pág. 22, nota de pié de pág. 12.

${ }^{64}$ Association Internationale de Droit Penal (AIDP)/Max Planck Institute for for Foreign and International Criminal Law (MPI) et al., 1994 ILC Draft Statute for an International Criminal Court with proposed modifications (updated Siracusa Draft), 1996, artículo 33-8.

${ }^{65}$ Véase la decisión de la Supreme Court de los Estados Unidos en In re Yamashita, 327 U.S. 1, 13-14 (1945): "... ignorando ilegalmente en contra de su deber como comandante el control de las actuaciones de sus subordinados, permitiéndoles cometer brutales atrocidades..." (traduc del inglés). Para más referencias véase AMBOS, "Individual Criminal Responsibility in International Criminal Law" en: G.K MCDONALD/O. Swaak GOLDMAN (eds.), Substantive and Procedural Aspects of International Criminal Law. The Hague (Kluwer) 1999. Recientemente, Ann Marie PROVOST que muestra que el precedente Yamashita estuvo fuertemente influenciado por motivos raciales de U.S. contra los japoneses (Race and War Crimes: The 1945 War Crimes Trial of General tomoyuki Yamashita, 14 Human Rights Quarterly 1992, 303).

${ }^{66}$ Resulta conveniente reproducir el texto del artículo 28 :

Responsabilidad de los jefes y otros superiores

Además de otras causales de responsabilidad penal de conformidad con el presente Estatuto por crímenes de la competencia de la Corte:

1. El jefe militar o el que actúe efectivamente como jefe militar, será penalmente responsable por los crimenes de la competencia de la Corte que hubieren sido cometidos por fuerzas bajo su mando y control efectivo, o su autoridad y control efectivo, según sea el caso, en razón de no haber ejercido un control apropiado sobre esas fuerzas cuando:

a) Hubiere sabido o, en razón de las circunstancias del momento, hubiere debido saber que las fuerzas estaban cometiendo esos crimenes o se proponian cometerlos; y 
- o proyectos - a las Convenciones de Ginebra ${ }^{67}$, en especial el artículo 86 (2) del Protocolo Adicional I, no hacen esta distinción si bien tratan más equitativamente a los militares y a los superiores civiles ${ }^{68}$. La distinción hecha en el Estatuto de Roma, vuelve a la propuesta de los Estados Unidos, cuyo fundamental objetivo fue introducir distintos límites subjetivos de responsabilidad civil y militar ${ }^{69}$. De acuerdo con ello, el comandante militar sería tenido por responsable - conforme al estándar reconocido por conocimiento ("o porque deba saber") o negligencia, si bien el superior civil sólo por conocimiento. Esto último no fue aceptado por muchas delegaciones que tomaron parte en las discusiones de carácter informal. Una propuesta no oficial de Argentina, Canadá y Alemania apuntó en favor de utilizar un criterio de negligencia en ambos $\operatorname{casos}^{70}$. Las posturas contrarias concluyeron finalmente, a modo de discusión informal presidida por Canadá, con el compromiso de reemplazar el criterio de negligencia del superior civil, por el texto "ignorando conscientemente la información que debería (claramente) permitirle concluir en las circunstancias del tiempo en que sus subordinados estaban cometiendo o iban a cometer el delito..." La palabra "claramente" fue incluida más tarde en el texto oficial ${ }^{71}$. Por ello, en una versión posterior el texto fue simplificado por "ignorando conscientemente la información que claramente indicaba que los subordinados estaban cometiendo o iban a cometer tales delitos"172.

b) No hubiere adoptado todas las medidas necesarias y razonables a su alcance para prevenir o reprimir su comisión o para poner el asunto en conocimiento de las autoridades competentes a los efectos de su investigación y enjuiciamiento.

2. En lo que respecta a las relaciones entre superior y subordinado distintas de las señaladas en el apartado a), el superior será penalmente responsable por los crímenes de la competencia de la Corte que hubieren sido cometidos por subordinados bajo su autoridad y control efectivo, en razón de no haber ejercido un control apropiado sobre esos subordinados, cuando:

a) Hubiere tenido conocimiento o deliberadamente hubiere hecho caso omiso de información que indicase claramente que los subordinados estaban cometiendo esos crímenes o se proponían cometerlos;

b) Los crímenes guardaren relación con actividades bajo su responsabilidad y control efectivo; y

c) No hubiere adoptado todas las medidas necesarias y razonables a su alcance para prevenir o reprimir su comisión o para poner el asunto en conocimiento de las autoridades competentes a los efectos de su investigación y enjuiciamiento.

${ }^{67}$ Véase supra nota 12. Comp, generalmente A.P.V. Rogers, Law on the Battlefield, 1996, págs. 138-142.

${ }^{68}$ Estatuto del Tribunal Penal Internacional para la Antigua Yugoslavia, U.N. Doc. S/RES/827 (1993), Annex, artículo 7 (3): "El hecho de que cualquiera de los actos mencionados en los artículos 2 a 5 del presente Estatuto haya sido cometido por un subordinado, no eximirá de responsabilidad penal a su superior si éste sabía o tenía razones para saber que el subordinado iba a cometer tales actos o los había cometido y no adoptó las medidas necesarias y razonables para impedir que se cometieran o para castigar a quienes los perpetraron."

${ }^{69}$ U.N. Doc. A/Conf. 183/C.1/L.2 (1998).

${ }^{70}$ Propuesta de Argentina, Canadá y Alemania, Jun. 17, 1998 (archivo del autor).

${ }^{71}$ UN Doc. A/CONF. 183/C.1/WGGP/L.7 (1998).

${ }^{72}$ UN Doc. A/CONF. 183/C.1/WGGP/L.7/Rev. 1 (1998). 
Dado lo anterior, resulta claro que el artículo 28 establece distintos criterios subjetivos para militares y para civiles. Sigue en pie la cuestión de cómo extender el tradicional criterio de "debería saber" ("should have known") que difiere del nuevo criterio para los superiores civiles del artículo 28 (2) (a). En respuesta, resulta que este nuevo criterio repite el conocido criterio del Common Law y de los juicios sobre crímenes de guerra consistente en "meter la cabeza debajo del ala" ("wilful blindness" $)^{73}$. El criterio de "ciego voluntario" tiene su excepción en el requisito del conocimiento positivo al considerarse que concurre este último - en relación con un hecho particular - "cuando una persona es consciente de la alta probabilidad de su existencia a menos que crea que no existe ${ }^{174}$. El conocimiento no se presume, aunque implique el resultado de la conducta defensiva ${ }^{75}$. El ciego voluntario $y$, por tanto, el nuevo criterio del artículo 28 (2) (a) se encuentra entre el conocimiento y la imprudencia. En otras palabras, se está ante una exigencia mayor que la negligencia ${ }^{76}$. De este modo, el Estatuto de Roma cambia la ley de responsabilidad del mando en relación con los superiores civiles y hace más difícil la acusación, por no ejercer adecuadamente el control. Además, se está ignorando la reciente aplicación de la tradicional doctrina de la responsabilidad del mando a los superiores civiles ${ }^{77}$.

Por un lado, la restricción del Estatuto de Roma a la responsabilidad del mando, al menos en el caso de los civiles, es el resultado de ciertas contradicciones dogmáticas de esta doctrina. En primer lugar, se duda de si la negligencia - todavía suficiente para los mandos militares (de facto) - puede relacionarse lógicamente con el intento de cometer un delito. ¿Cómo, por ejemplo, puede un mando militar cometer por negligencia un delito contra la Humanidad que exige aparte de la mens rea general (véase infra artículo 30), un específico conocimiento para la comisión "como parte de un ataque extenso o sistemático" (artículo 7)? ¿Cómo puede haber intención de destruir (artículo 6) si no se sabe que los subordinados están cometiendo el delito? El profesor William A. Schabas ha afirmado correctamente que "lógicamente es imposible

\footnotetext{
${ }^{73}$ Véase por ejemplo, R. V. FINTA (1990), 92 D.L.R. ( $\left.4^{\text {th }}\right)$ 1, 1 O.r. (e ed) 183, 98 I.L.R. 520 (Ontario C.A.), en 595 (I.L.R.).

${ }^{74}$ Véase MPC, supra nota 28, o 2.02 (7). Véase también LAFAVE Wayne R. / SCOTT, Austin W. Criminal Law 1 307-8 (1986).

${ }^{75}$ Comentario a MPC, supra nota $28,02.02$

${ }^{76}$ Véase también SCHABAS, supra note 3, pág. 419 que considera el nuevo criterio como una "exigencia de pleno conocimiento".

${ }^{77}$ Véanse las decisiones del ICTY bajo la regla 61, Rules of Procedure and Evidence, U.N. Doc, IT/32: Prosecutor v. Nikolic (Case No. IT-94-2-R 61), Oct. 20, 1995, para. 24; Prosecutor v. Karadzic and Mladic (Cases Nos. IT95-5-R 61/IT-95-18-R 61), Jul. 11, 1996, paras. 42.65-85. Véase también las últimas decisiones del ICTR: Prosecutor v. Kambanda, supra nota 52, par. 40; Prosecutor v, Akayesu, supra nota 52, par. 487-91, donde, sin embargo, se afirma que la responsabilidad de mando de los civiles "queda en discusión" (par, 491).
} 
cometer un delito de intención por negligencia" ${ }^{178}$. El nuevo criterio para los superiores civiles parece mostrar un camino fuera de la lógica.

En segundo lugar, debe hacerse hincapié en que la responsabilidad del mando comprende también la responsabilidad por omisión $n^{79}$ El superior puede ser castigado por su falta de control sobre los subordinados y por no impedir o reprimir la comisión de atrocidades. Ciertamente, el superior sólo es responsable en caso de ostentar una efectiva autoridad y control (lo cual ocurre especialmente en el caso del superior civil) artículo 28 (2) (b) ${ }^{80}$ y sólo si no adopta todas las medidas necesarias y razonables; el superior es, por tanto, conceptualmente responsable por omisión, por no impedir las atrocidades cometidas por sus tropas, y fundamentalmente por perder el control sobre las mismas en el supuesto de ser posible conservar tal control. Esta responsabilidad por omisión es única en Derecho penal internacional. El Estatuto de Roma confirma esta regla al eliminar ${ }^{81}$ la disposición general sobre hechos $\mathrm{y} / \mathrm{u}$ omisiones ${ }^{82}$ en base al argumento de que sólo el artículo 28 contempla la responsabilidad por omisión ${ }^{83}$. Sin embargo, esta responsabilidad por no actuar se contrapone, desde un punto de vista objetivo, a la efectiva autoridad y control del superior; la posibilidad de control constituye la base legal y legítima sobre la que descansa la responsabilidad del superior, lo que justifica su deber de intervención ("Garantenpflicht") y, finalmente, implica la equivalencia moral entre la falta de evitación del daño y la causación activa del mismo.

No obstante ello, en los casos en que la legitimidad de la responsabilidad del mando se cuestiona considerablemente (en el caso de conocimiento positivo del superior), la delimitación entre la responsabilidad por omisión ("command responsibility") y la actuación como cómplice (complicity) es vaga. Al margen de las similitudes existentes entre estas dos formas de responsabilidad derivada ${ }^{84}$, la prueba en los juicios sobre crímenes de guerra permite normalmente concluir en ambas direcciones. Un superior que tenga conocimiento de las atrocidades cometidas por sus tropas, puede ser tenido por responsable como cómplice (ayudando y encubriendo) por, al menos psicológicamente, alentar y animar a las tropas; el superior también puede ser responsable mediato del mando, por no impedir las atrocidades. De hecho, el ICTY en

\footnotetext{
${ }^{78}$ SCHABAS, supra note 3, pág. 417. También crítico; WISE, supra nota 7, en 46.

${ }^{79}$ Véase la discusión crítica de FLETCHER (1998), supra nota 2, en 45-50.

${ }^{80}$ Articulo 28 (2) (b) es innecesario en cuanto que sólo repite la exigencia de efectivo control ya mencionada en la primera frase del subparágrafo 2 .

${ }^{81}$ U.N. Doc. A/CONF. 183/C.1/WGGP/L.4/Add.1 (1998).

${ }^{82}$ Draft Statute for the International Criminal Court, supra nota 5, artículo 28.

${ }^{83}$ WISE, supra nota 7 , en $48-50$, afirma la regla general por omisión.

${ }^{84}$ Comp. FLETCHER (1978), supra nota 2, en 582-583.
} 
sus resoluciones de Regla $61^{85}$ ha utilizado ambas formas de responsabilidad. Por ejemplo, Karadzic y Mladic fueron juzgados responsables como comandantes ${ }^{86}$ de planear el genocidio y de no impedirlo, así como por otros delitos. Esta responsabilidad paralela puede inducir a confusión ${ }^{87}$, pero es una consecuencia del reconocimiento de la responsabilidad de mando. La aparente contradicción, puede reconciliarse arguyendo una prevalencia de la responsabilidad por hechos sobre la responsabilidad por omisión (principio de subsidiariedad) si las diferentes formas de conducta en cuestión se encuentran temporal y subjetivamente interrelacionadas ${ }^{88}$.

\section{Elementos subjetivos de la responsabilidad penal individual (mens rea)}

Además de los especiales requisitos subjetivos ya mencionados, el artículo 30 exige, que los elementos materiales de un delito perteneciente a la jurisdicción del Tribunal se realicen con intención y conocimiento ${ }^{89}$. La fórmula "a menos que se prevea otra cosa", reconoce excepciones, en especial las menores exigencias del artículo 28 ("command responsibility"). El Proyecto de Código de 1996 no prevé tal excepción y establece, sin embargo, exigencias menores de carácter subjetivo para algunos delitos ${ }^{90}$. Allain y Jones han puntualizado que el requisito de la "intencionalidad" utilizado en muchos textos de las Convenciones de Ginebra ${ }^{91}$ (artículo 8 (2) (a) (iv) del Estatuto de Roma) corresponde más a "recklessly" que a "intentionally" y por tanto, supone una

\footnotetext{
${ }^{85}$ Rules of Procedure and Evidence, supra nota 2, en 582-583.

${ }^{86}$ Prosecutor v. Karadzic and Mladic, supra nota 76 , paras. 84,94

${ }^{87}$ SCHABAS, supra note 3, pág. 416 nota de pié de pág. 133

${ }^{88}$ Tal prevalencia se encuentra en Prosecutor v. Karadzic and Mladic, supra nota 76, para. 83: "Las pruebas y testimonios coinciden en demostrar que Radovan Karadzic y Radko Mladic no sólo estaban informados de los crimenes supuestamente cometidos bajo su autoridad, sino también $y$, en especial, que ejercian su poder para planear, instigar, ordenar y de cualquier otro modo ayudar y alentar la preparación, planeamiento o ejecución de los mencionados delitos". (traduc. del inglés).

89 "Artículo 30. Elemento de intencionalidad (mens rea).
}

1. Salvo disposición en contrario, una persona será penalmente responsable y podrá ser penada por un crimen de la competencia de la Corte únicamente si actúa con intención y conocimiento de los elementos materiales del crimen.

2. A los efectos del presente artículo, se entiende que actúa intencionalmente quien:

a) En relación con una conducta, se propone incurrir en ella;

b) En relación con una consecuencia, se propone causarla o es consciente de que se producirá en el curso normal de los acontecimientos.

3. A los efectos del presente artículo, por 'conocimiento' se entiende la conciencia de que existe una circunstancia o se va a producir una consecuencia en el curso normal de los acontecimientos. Las palabras 'a sabiendas' y 'con conocimiento' se entenderán en el mismo sentido."

${ }^{90}$ Supra nota 20, articulo 2 (3) (a)

${ }^{91}$ Por ejemplo, la Convención de Ginebra de 12 de agosto de 1949 relativa a la protección de civiles, supra nota 12 , artículo 147. 
exigencia menor ${ }^{92}$. Así, la fórmula "a no ser que se prevea otra cosa" es un caveat necesario.

La cuestión consiste, entonces, en determinar si el artículo 30 excluye por definición un más bajo nivel de exigencia que la tentativa y el conocimiento. De acuerdo con el parágrafo 2 , tentativa significa que una persona realiza cierta conducta o desea producir ciertas consecuencias o es consciente de que la misma tendrá lugar en el curso ordinario de los acontecimientos. ¿Excluye esta definición alguna exigencia de menos importancia? Ciertamente, la "falta de diligencia" no puede ser la base de la responsabilidad una vez suprimida la correspondiente previsión ${ }^{93}$. Lo mismo es de aplicación para el dolo eventual: este es un tipo de "intención condicional" que engloba un amplio conjunto de actitudes positivas dirigidas a la producción de un resultado y por ello, supone una exigencia mayor que la "falta de diligencia" ${ }^{194}$. El autor puede ser indiferente al resultado o no dar importancia al daño producido en el bien jurídico ("sich mit der Rechtsgutsverletzung abfinden") 95 . Sin embargo, el autor no es consciente, como exige el artículo 30 (2) (b), del resultado o consecuencia que tendrá lugar en el curso ordinario de los acontecimientos. Él o ella sólo piensa que el resultado es posible. Así, el texto del artículo 30 , apenas deja espacio para una interpretación que incluya el dolo eventual en el concepto de tentativa como una especie de "dolo indirecto" 196 . Finalmente, existe una cuestión terminológica. Ser consciente significa que el autor sabe que el resultado dañoso tendrá lugar. De hecho, el artículo 30 (3) define conocimiento, como "consciencia de que una circunstancia existe o una consecuencia tendrá lugar en el curso normal de los acontecimientos". Esto muestra que el artículo 30 ignora la diferencia entre "tentativa" y "conocimiento", mezclando dos diferentes categorías de conducta, caracterizadas en la doctrina alemana como conocer y querer ("Wissen und Wollen") $)^{97}$. También en la moderna Common Law se distingue entre "propósito", "conocimiento", "falta de diligencia" y "negligencia"98.

\footnotetext{
92 ALLAIN/JONES," A Patchwork of Norms: A Commentary on the 1996 Draft Code of Crimes against the Peace and Security of Mankind", 8 European Journal of International Law (EJIL) 1997, 100, 106.

${ }^{93}$ Véase Draft Statute for the International Criminal Court, supra nota 5, artículo 29 (4). No se ha alcanzado el consenso sobre una definición común.

${ }^{94}$ La "recklessness" se encuentra entre el dolo eventual y la negligencia consciente (bewusste Fahrlössigkeit). Véase WEIGEND, "Zwischen Vorsatz und Fahrlässigkeit", 93 ZStW 657, 673 y sig. (1981).

${ }^{95}$ Comp. FLETCHER (1978), supra nota 2, en 446, y FLETCHER (1998), supra nota 2, en 123. Para las diversas teorías en Alemania véase ROXIN, supra nota 9, en 372-400.

${ }^{96}$ Pero compárese WISE, supra nota 7 , en $52-4$, que da una definición que incluye el dolo eventual pero excluye el "recklessness".

${ }^{97}$ De modo similar WISE, supra nota 7, en 51 .

${ }^{98}$ Comp. MPC, supra nota $28,02.02$.
} 


\section{DEFENSAS Y CAUSAS ESPECIALES DE EXCLUSIÓN DE RESPONSABILIDAD PENAL (ARTS. 26, 27, 29, 31-33)}

Para lograr los objetivos de nuestro análisis nos ha parecido bien hacer una distinción entre las defensas de índole procesal (artículos 26, 27, 29), las causas generales de exclusión de responsabilidad (parágrafos (a) y (b) del artículo 31 (1)) y las causas de justificación y exoneración (artículos 31 (1) (c) y (d), 32 y 33).

\section{Defensas procesales}

El artículo 26, prevé una solución jurisdiccional en relación con la edad de responsabilidad penal debido a la imposibilidad de llegar a un consenso en este punto. Las propuestas rondaron desde los 13 hasta los 21 años. Ahora el Tribunal carece de jurisdicción sobre personas que estén por debajo de los 18 años al tiempo de comisión de los hechos. Así, se ha omitido definir de manera general la edad de responsabilidad.

La capacidad oficial, invocada por un Jefe de Estado o persona que ocupe otra posición pública, se excluye como defensa o como un motivo de reducción de la pena por el artículo $27^{99}$. La inmunidad $u$ otras reglas procesales tampoco pueden considerarse obstáculos procesales. Esta es una de las pocas previsiones que ha sobrevivido desde Nuremberg $\sin$ haber sido modificada ni rechazada ${ }^{100}$. Uno de los pocos trabajos en discusión durante los esfuerzos de codificación tras la Segunda Guerra Mundial, ha tratado de si la regla se extiende a todos los oficiales públicos, desde el primero en graduación hasta el último. La Convención del Genocidio de 1948 limitó la regla a "todos los legisladores constitucionalmente responsables"

\footnotetext{
99 "Artículo 27 Improcedencia del cargo oficial

1. El presente Estatuto será aplicable por igual a todos sin distinción alguna basada en el cargo oficial. En particular, el cargo oficial de una persona, sea Jefe de Estado o de Gobierno, miembro de un gobierno o parlamento, representante elegido o funcionario de gobierno, en ningún caso la eximirá de responsabilidad penal ni constituirá per se motivo para reducir la pena.

2. Las inmunidades y las normas de procedimiento especiales que conlleve el cargo oficial de una persona, con arreglo al derecho interno o al derecho internacional, no obstarán para que la Corte ejerza su competencia sobre ella."

${ }^{100}$ Véase: Agreement for the Procecution and Punishment of Major War Criminals of the European Axis, and Establishing the Charter of the International Military Tribunal (I.M.T), aprobado el 8 de agosto de 1945, 82 U.N.T.S. 279, articulo 7; Control Concil Law No. 10, Punishment of Persons Guilty of War Crimes, Crimes Against Peace and Against Humanity, December 20, 1945, Official Gazette Control Council for Germany, art. II(4)(a): Principles of International Law recognized in the Charter of the Nürnberg Tribunal and in the Judgment of the Tribunal, supra nota 15, Principle III; Convention for the Prevention and Punishment of the Crime of Genocide, adopted Dec. 9, 1948, 78 U.N.T.S. 277 (entered into force Jan. 12, 1951), art. IV: ICTY-Statute, supra nota 67, art. 7(2); Statute of the International Criminal Tribunal for Rwanda (ICTR), U.N. Doc. S/RES/955 (1944). Annex, art. 6(2).
} 
considerando las reglas de inmunidad nacional"101; por otro lado, resultó controvertido si entre los "oficiales públicos" también debía incluirse a los miembros electos del Parlamento ${ }^{102}$. El Proyecto de Código de la ILC de 1991 (artículo 13) y de 1996 (artículo 7) extiende la previsión a Jefes de Estado, Ministros y oficiales públicos, aunque el Proyecto de 1954 (artículo 3) no incluyó de forma clara a los ministros ${ }^{103}$. Por otro lado, inicialmente el ILC no quiso excluir la posibilidad de mitigación del castigo explícitamente: se rechazó una propuesta ${ }^{104}$ durante las deliberaciones del Proyecto de Código de $1954^{105}$. La decisión tuvo que dejarse en manos del Tribunal. Esta posición fue mantenida en el Proyecto de 1991, si bien el de 1996 (artículo 7) excluyó cualquier reducción del castigo. La Comisión de Derecho Internacional, sin embargo, no consideró necesario excluir la inmunidad procesal explícitamente. Su exclusión fue considerada un lógico corolario a la falta de inmunidad sustantiva ${ }^{106}$. Todos estos puntos fueron incluidos en el artículo 27 del Estatuto de Roma, y resueltos en favor de una acusación sin límites contra aquellos que actúen amparándose en su oficialidad. ${ }^{107}$

Cualquier plazo de prescripción para los delitos comprendidos en la jurisdicción del Tribunal está excluido en el artículo 29. Tal regla, es posible a causa de que la jurisdicción del Tribunal, está limitada a los delitos definidos en los artículos 5 a 9 , es decir, crimenes de extrema gravedad. En anteriores instrumentos o proyectos, o bien no se excluía la prescripción o bien quedaba la duda acerca de los delitos a incluir en el instrumento ${ }^{108}$. Schabas puntualizó acertadamente, que podía surgir un problema de complementariedad cuando la acusación de un delito fuera obstaculizada por plazos de prescripción contemplados en el derecho nacional, pero su persecución fuera posible por el ICC ${ }^{109}$. En tales casos, la regla de complementariedad (artículo 17), si el ICC

${ }^{101}$ Convention for the Prevention and Punishment of the Crime of Genocide, ibid, artículo IV. Crit. Graven, supra nota 47, en 508 y sig.; PLANZER, Le crime du genocide 136-137 (1956).

102 Véase Peter N. DROST, The Crime of State, tomo 2, Genocide 8, 94 (1959) (proponiendo el término "agente del Estado"); véase también N. ROBINSON, The Genocide Convention 70-71 (1960),

${ }^{103}$ D.H.N. JOHNSON, "The Draft Code of Offenses against the Peace and Security of Mankind", 4 International \& Comparative Law Quarterly 1955, $462-463$ (462-3).

104 Jean SPIROPOULUS, Report, in Yearbook ILC 1950, tomo II, págs. 253-278, 273.

${ }^{105}$ Yearbook ILC 1954, tomo I, p.138; Yearbook ILC 1951, tomo II, págs 51-52.

106 "Report of the ILC on the work of its forty-eighth session, 5 de junio-26 de agosto, 1996, supra nota 18, en 41 (para. 6).

107 Sobre el caso Pinochet al respecto ver AMBOS, "El caso Pinochet y el Derecho aplicable". Revista Penal (España) 1999, no. 1, pág. 3 sgs. (11 sgs.).

${ }^{108}$ El Proyecto de Código de 1991, supra nota 19, artículo 7, excluyó un plazo de prescripción pero la previsión fue suprimida durante las discusiones sobre el Proyecto de Código de 1996 (supra nota 20), porque se consideró que tal regla no se aplicaria a todo delito previsto en el Código (Véase Yearbook ILC 1994, tomo II, págs. 80-81, paras. 147 y sigs.; Yearbook ILC 1994, tomo I, pág. 146, para 16).

${ }^{109}$ Ver SCHABAS, supra note 3, pág. 419. 
asumiría la jurisdicción, sería eludida. Puede afirmarse sin embargo, que hoy en día con la posición predominante del Derecho Internacional, no se admiten plazos de prescripción para tales delitos, por lo cual se debe corregir la legislación nacional en estos casos. Si un Estado no lo admitiera, demostraría su desinterés en la persecución de tales delitos, no pudiéndose invocar el principio de complementariedad.

\section{Las causas generales de exclusión de responsabilidad}

Los subparágrafos (a) y (b) del artículo 31 (1) prevén la exclusión de responsabilidad en base a la capacidad de controlar y determinar su propia conducta ${ }^{110}$. Hay, sin embargo, una diferencia fundamental entre las dos previsiones que apunta al grado de imputabilidad del autor: en caso de padecer una dolencia o incapacidad mental (subparágrafo (a)), el autor no puede ser culpado por su conducta ilegal ya que, normalmente, no se ha causado dicha dolencia o incapacidad, o al menos no en orden a cometer un delito sin culpabilidad. El autor no puede "apreciar la ilicitud o naturaleza de su conducta" (artículo 31 (1) (a)), o bien carece de capacidad para controlarla dentro del margen que permite la ley a causa de una dolencia o enfermedad. El autor no sabe lo que está haciendo y por tanto no actúa culpablemente ${ }^{111}$. En caso de intoxicación (artículo 31 (1) (b)) la situación es sustancialmente diferente, porque quien toma de forma libre y autónoma la decisión de beber alcohol sabe normalmente que afectará a su capacidad de control y apreciación. Partiendo de esta premisa, es comprensible la controversia suscitada en relación con las consecuencias legales de un estado de intoxicación. La mayoría de los países árabes, regidos por la ley islámica, consideran el (excesivo) consumo de alcohol como un factor agravante, mientras los países occidentales, como consecuencia de la legalización del consumo de alcohol, en principio lo consideran como un factor de reducción o incluso de exclusión del castigo. Así, el consenso en la Conferencia de Roma sólo fue posible incluyendo una nota por la que "la intoxicación voluntaria como causa de exoneración de responsabilidad criminal no se aplicaría generalmente en casos de genocidio o crímenes contra la humanidad, pero podría aplicarse a casos aislados que supusieran asimismo crímenes de guerra" ${ }^{112}$.

110 "1. Sin perjuicio de las demás circunstancias eximentes de responsabilidad penal establecidas en el presente Estatuto, no será penalmente responsable quien, en el momento de incurrir en una conducta:

a) Padeciere de una enfermedad o deficiencia mental que le prive de su capacidad para apreciar la ilicitud o naturaleza de su conducta, o de su capacidad para controlar esa conducta a fin de no transgredir la ley;

b) Estuviere en un estado de intoxicación que le prive de su capacidad para apreciar la ilicitud o naturaleza de su conducta, o de su capacidad para controlar esa conducta a fin de no transgredir la ley, salvo que se haya intoxicado voluntariamente a sabiendas de que, como resultado de la intoxicación, probablemente incurriria en una conducta tipificada como crimen de la competencia de la Corte, o haya hecho caso omiso del riesgo de que ello ocurriere;"

${ }^{111}$ Véase también la parecida previsión de MPC, supra nota 28, 04.01.

${ }^{112}$ U.N. Doc. A/CONF. 183/C.1/WGGP/L. 4/Add. 1/Rev. 1 (1998), pág, 4, fn. 8. 
El campo de aplicación del subparágrafo (b) está limitado por la adopción del principio de la actio libera in causa ("a no ser que la persona se haya intoxicado voluntariamente..."). La idea fundamental de este principio consiste en prevenir la intoxicación de mala fe; por ejemplo, la intoxicación con el objetivo de cometer un delito en un estado de no responsabilidad y después invocar este estado como causa de exclusión de responsabilidad. Este principio está generalmente reconocido tanto en el Derecho continental como en el del Common Law ${ }^{113}$ y codificado en muchos códigos nacionales ${ }^{114}$. Sin embargo, es bastante difícil probar que alguien ha bebido voluntariamente para cometer un delito. Por esta razón y a causa de que la conducta humana se encuentra bajo los efectos del alcohol, el Common Law no reconoce en principio la intoxicación como defensa ${ }^{115}$, al menos cuando uno mismo se coloca en dicha situación; mientras el modelo continental, prevé un delito específico en caso de crímenes cometidos en estado de intoxicación $n^{116}$. Este delito está basado en la negligencia (como riesgo de cometer un delito en estado de intoxicación) y está en conflicto con el elemento subjetivo de los delitos comprendidos en la jurisdicción del Estatuto, como contemplado extensamente el artículo 28. Esto muestra que la posición de los Estados Árabes no era del todo descartable y que la nota al pie estaba bien fundada. De hecho, si el alcance del subparágrafo (b) está realmente limitado a "actos aislados constitutivos de crímenes de guerra", es realmente apropiado para el ICC conocer tanto de la acusación de soldados que cometen crímenes de guerra en estado de embriaguez, como de juzgar a las autoridades y superiores civiles y militares responsables generalmente del planeamiento y organización de las atrocidades ${ }^{117}$.

\section{Causas de justificación y exoneración}

El Estatuto reconoce en el artículo 31 (1) (c) ${ }^{118}$ la proporcional legítima defensa propia y de terceros contra un inminente e ilegal uso de la fuerza. Aunque se reconoció

113 Comp. FLETCHER (1978), supra nota 2, en 846-7. Véase también MPC, supra nota 28, o 2.08 (2) y comentarios en 357 .

${ }^{114}$ Véase por ejemplo el CP alemán, § 12, el CP italiano, artículo 92 - más recientemente - el CPesp, artículo 20. núm. 1 (2): "El trastorno mental transitorio no exime de pena cuando hubiese sido provocado por el sujeto con el propósito de cometer el delito o hubiera previsto o hubiera podido prever su comisión."

115 Véase MPC, supra nota 28, 2.08, y comentario en 350 y sigs. por un lado, y 4.01 por otro. Véase también FLETCHER (1978), supra nota 2, en 847-52.

${ }^{116}$ Véase por ejemplo el CP alemán, § 323 a: "Quien intencional o negligentemente llegue a un estado de intoxicación ... será castigado ... si mientras se encuentra en dicho estado comete un hecho antijurídico y no puede ser castigado ..." (traduc, del alemán)

117 Incluso más drástica: SCHABAS, supra note 3, pág. 423: "... la previsión... alcanza el absurdo" (traduc. del inglés).

${ }^{118}$ Art. 311 (c):

c) Actuare razonablemente en defensa propia o de un tercero o, en el caso de los crímenes de guerra, de un bien que fuese esencial para su supervivencia o la de un tercero o de un bien que fuese esencial para realizar una misión 
por la ILC ${ }^{119}$, con anterioridad no existía codificación alguna, excepto en conexión con delitos contra la paz ${ }^{120}$. Más controvertida fue la inclusión de la defensa de la propiedad propuesta por los Estados Unidos de América y por Israel, invocando previsiones constitucionales e insistiendo en que "la defensa de la propia casa puede estar perfectamente legitimada." Los Estados Unidos propusieron un tratamiento igualitario de defensa de la vida y de la integridad física por un lado y de la propiedad por otro ${ }^{121}$. La posición de los. Estados Unidos no fue bien acogida, y el texto final del subparágrafo (c) muestra que la protección de la propiedad se limita a las situaciones de crímenes de guerra en las que resulta esencial "para la supervivencia de la persona o de terceros" 0 , asimismo, "esencial para cumplir una misión militar"122. Otras limitaciones adicionales, como las propuestas por Alemania (separando las frases relativas a la propiedad de las demás para que la redacción resulte más clara), fueron rechazadas por la delegación de los Estados Unidos.

La última frase del subparágrafo (c) aclara la diferencia entre la propia defensa individual y la colectiva ${ }^{123}$. La participación en la defensa colectiva ${ }^{124}$ no excluye por sí misma la responsabilidad penal a menos que la persona en cuestión se haya comportado dentro de los límites de la propia defensa individual, como expresa la primera frase del subparágrafo (c). La propia defensa colectiva se rige por el artículo 51 de la Carta de Naciones Unidas ${ }^{125}$.

La eximente por "duress" (estado de necesidad por coacción o amenaza), se encuentra contemplada en el artículo 31 (1) (d). Se exige: (1) una amenaza de muerte inminente o de continuos y graves daños corporales contra la persona en cuestión o una tercera persona; (2) una reacción necesaria y razonable dirigida contra dicha amenaza; (3) a nivel subjetivo, el correspondiente dolus (no pretender causar un daño mayor que

militar, contra un uso inminente e ilícito de la fuerza, en forma proporcional al grado de peligro para él, un tercero - los bienes protegidos. El hecho de participar en una fuerza que realizare una operación de defensa no bastará para constituir una circunstancia eximente de la responsabilidad penal de conformidad con el presente apartado:

119 Yearbook ILC, 1994, tomo II, pág. 84.

${ }^{120}$ Véase el Proyecto de Código de 1954, supra nota 16, artículo 2 (1), (3).

${ }^{121}$ U.N. Doc A/CONF. 183/C.1/WGGP/L.2 (1988).

122 Comp. U.N. Doc A/CONF. 183/C.1/WGGP/L. 4/Add 1(1988), páds. 4.5 y U.N. Doc A/CONF. 183/C.1/WGGP/L.4/Add. 3 (1988), pág. 2.

${ }^{123}$ Véase también Yearbook ILC 1994, tomo II, pág. 84 (para. 178); Doudou Thiam, Twelfth Report, U.N. Doc. A/CN, 4/460 (1994), para. 159.

${ }^{124}$ Algunas delegaciones eran del punto de vista de que esto sólo se aplicara a lícitas operaciones defensivas (U.N. Doc. A/CONF/.183/C.1/WGGP/L.4/Add. 3 (1998), pág.2, fn. 3).

${ }^{125}$ Véase también la nota a pie de página de "accomplishing a military mission which declares that the use of force by States is governed by the applicable international law" (U.N. Doc. A/CONF.183/C.1/WGGP/L.4/Add. 3 (1998), pág.2, nota de pié de pág. 1). 
el que debe ser evitado). Esta eximente ha sido reconocida por el ILC ${ }^{126}$, el Comité Ad Hoc de la Asamblea General y por el PrepCom ${ }^{127}$. El Proyecto, sin embargo, confunde diferentes conceptos relacionados con la "duress" por un lado, y con la necesidad por el otro ${ }^{128}$. Se reconoce, generalmente, que "duress" se refiere a una ausencia de libertad de voluntad o de elección en relación con una amenaza inmediata ${ }^{129}$, mientras que la necesidad se basa en elegir de entre todos el mal menor ${ }^{130}$. En caso de necesidad la incriminación desaparece en favor de la protección de un bien mayor; la necesidad justifica una conducta por sí misma ilegal ${ }^{131}$. Por otro lado, en el caso de "duress" no puede invocarse tal justificación; sólo puede argüirse que el acusado no puede resistir la amenaza de ninguna otra manera. En otras palabras, la base racional de "duress" no es la ponderación de diferentes intereses legales, sino el criterio de "Zumutbarkeit" (puede esperarse razonablemente que la persona en cuestión resistirá la amenaza) ${ }^{132}$. Por tanto, "duress" es una causal de exculpación ${ }^{133}$.

El subparágrafo (d) utiliza elementos de ambos conceptos. La "amenaza" se refiere tanto a la necesidad como a la "duress", mientras que la "reacción razonable y necesaria" se refiere sólo a necesidad, introduciendo un nuevo requisito subjetivo relacionado con la elección de un mal menor. Así, la distinción entre una amenaza hecha por personas y una amenaza constituida por otras circunstancias fuera del control de la persona amenazada se refiere a "duress" (en el primer caso) y a necesidad (en el segundo $)^{134}$. En suma, el Proyecto confirma la vaguedad conceptual de esta materia en Derecho penal internacional ${ }^{135}$. La previsión, no obstante, constituye un avance en cuanto reconoce "duress" como eximente, dejando a un lado la

\footnotetext{
${ }^{126}$ Yearbook ILC 1994, tomo II, pág. 87 (paras, 206-207).

${ }^{127}$ Véanse las referencias de SCHABAS, supra note 3, pág. 425.

${ }^{128}$ Véase también WISE, supra nota 7, en 57.

129 Cf. ROBINSON, Criminal Law defences II 351 (1984): "relative impairment of the psychological control mechanisms."

${ }^{130}$ Comp. MPC, supra nota $28,2.09$ y 3.02.

131 Véase MPC, supra nota 28, 3.02, comentario, en 9: "... un principio de necesidad... exige una justificación general de conducta, que de cualquier otro modo constituiría un delito."

132 Véase el CP alemán, § 35, y Fletcher (1978) supra nota 2, en 833, Véase también MPC, supra nota 28, 2.09 (1), que sin embargo, emplea un mejor criterio objetivo ("reasonable firmess).

${ }^{133}$ Véase generalmente para la necesaria diferencia entre justificación y eximente: ESER, "Justification and excuse: A key issue in the concept of crime", en: ESER/FLETCHER (eds.), Rechtfertigung und Entschuldigung. Justification and Excuse tomo I, 1987, págs. 17 sgs.; FLETCHER (1978), supra nota 2, at 759-774; ROBINSON supra nota 129, §24, 25; en contra de la distinción: GREENAWALT, "The perplexing borders of justification and excuse", in: ESER/FLETCHER (eds.), op. cit., at 265; también escéptico: HUSAK. "The Serial View of criminal Law Defences", 3 Crim. L.F. 369 (1992).

${ }^{134}$ Cf, ESER, "Defences" in War Crime Trials, 24 Israel Yearbook of Human Rights 1995, 201-202, 213.

${ }^{135}$ Recientemente, Christiane NILL-THEOBALD ha intentado desarrollar algunas reglas generales ("Defences" bei Kriegsverbrechen am Beispiel Deutschlands und der USA, Freiburg i. Br. 1998).
} 
desafortunada jurisprudencia del ICTY ${ }^{136}$. Finalmente el ICC podrá minimizar el daño causado con el texto del Proyecto al aplicar "las causas de exclusión de responsabilidad penal previstas en este Estatuto en todos los casos" (artículo 31 (2)).

La solución prevista en el artículo 32, en relación con el error de hecho o de derecho, se basa en la tradición del Common Law por la que un error es sólo admisible si constituye la negación de la mens rea. ${ }^{137}$ Así, un error de hecho normalmente excluye la responsabilidad criminal mientras que un error de derecho sólo excepcionalmente ya que sólo el primero niega el mens rea ${ }^{138}$. El error legal sólo se reconoce explícitamente en el caso de errónea comprensión de la licitud de una orden (artículo 33 (1) (b), véase infra). Por tanto, el Estatuto sigue la doctrina del "error iuris nocet". Pero ello no cubre todos aquellos supuestos en los que, por consideraciones de justicia, el error debería considerarse como eximente. El artículo 32 es similar al $2.04 \mathrm{MPC}$ en la medida en que considera el elemento mental, como factor determinante de la relevancia o irrelevancia de un error. Se trata, sin embargo, de una previsión más estricta que la del $\mathrm{MCP}$ en cuanto reconoce la legalidad de la propia conducta sólo en el caso de obediencia a una orden superior y no, como en el caso del parágrafo 2.04 (3) MPC, en el supuesto de ignorancia de la ley o de actuación en consonancia razonable con lo legalmente determinado. Aunque el MPC siga una práctica no del todo definida ${ }^{139}$, se reconoce al menos que la referencia al elemento mental no cubre todos los casos posibles. Sin embargo, tanto el MPC como el Estatuto de Roma son limitados en la medida en que no contemplan toda posible falta y así no permiten a los jueces encontrar soluciones dogmáticamente correctas y justas. Dado el limitado espacio de

\footnotetext{
${ }^{136}$ Prosecutor v. Erdemovic (IT-96-22-A), Oct. 7, 1997, para. 19, y disposición 4 (véase Olivia Swaak-Goldman, American Journal of International Law 1998, 282). Véase en especial - contra una defensa - el voto particular de McDonald/Vohrah, para. 59 y sigs. (en 66-7, 72, 75, 78, 88). Sin embargo, CASSESE argumenta mucho más convincentemente en favor de una defensa, para. 11 y sigs. (en 12, 16-7, 21 y sigs., 41 y sigs., 49-50), - Véase también, sobre la decisión de la Trial Chamber (en favor de una defensa): YEE, "The Erdemovic Sentencing Judgment: A Questionable Milestone for the International Criminal Tribunal for the Former Yugoslavia", Georgia Journal of int. \& Comp. L. 1997, 263, 295-302. - Contra "duress" (o necesidad) como eximente de asesinato o de genocidio véase DINSTEIN, The Defence of "Obedience to Superior Orders" en International Law 80 (1965); el mismo, International Criminal Law, 20 Israel L. Rev. 206, 235 (1985); seguido por MEZZETI, "Grounds for excluding criminal responsibility", en: LATTANZI, supra nota 11, 147-157 (152-153).

137 "Articulo 32 Error de hecho o error de derecho

1. El error de hecho eximirá de responsabilidad penal únicamente si hace desaparecer el elemento de intencionalidad requerido por el crimen

2. El error de derecho acerca de si un determinado tipo de conducta constituye un crimen de la competencia de la Corte no se considerará eximente. Con todo, el error de derecho podrá considerarse eximente si hace desaparecer el elemento de intencionalidad requerido por ese crimen o si queda comprendido en lo dispuesto en el artículo 33 del presente Estatuto."

${ }^{138}$ LAFAVE/SCOTT, supra nota 73, en 575 y sigs.; SMITH/HOGAN, Criminal Law, $9^{\text {th }}$ ed. 1999, págs. 79 y sigs.; véase también Jens WATZEK, Rechtfertigung und Entschuldigung im englischen Strafrecht 275 y sigs Freiburg im Breisgau 1997.

${ }^{139}$ Véase FLETCHER (1998) supra nota 2, págs. 153-4
} 
este artículo, no es posible extenderse más sobre toda posible situación donde un error pueda ser de relevancia ${ }^{140}$; un caso histórico y reciente puede servir como ejemplo. En Erdemovic, el acusado reconoció su culpa, pero al mismo tiempo, invocó la eximente de "duress"141. Como ya se ha mencionado, la Cámara de Apelación rechazó esta defensa por consideraciones generales ${ }^{142}$. La solución correcta habría consistido en examinar si Erdemovic actuó objetivamente en una situación de "duress": si no era este el caso, debería haberse considerado si el acusado creía estar actuando bajo "duress". Tal error respecto a una causal de exculpación ${ }^{143}$ sería irrelevante de acuerdo con el artículo 32 del Estatuto, porque no niega el mens rea de Erdemovic concerniente al delito que cometió. Considerado como error puede eliminar la imputabilidad o culpabilidad de la conducta en cuestión, como ocurre con cualquier eximente (por ejemplo, enajenación mental). Subyace con todo la cuestión de si resulta justo castigar a quien piensa haber actuado de acuerdo con las exigencias éticas de la ley. Ciertamente, resulta controvertido clasificar este ejemplo y el consiguiente reconocimiento del "duress" como una eximente relevante. El argumento es mucho más evidente cuando se trata de normas de justificación. Si por ejemplo, un acusado cree, erróneamente, haber actuado en defensa propia, necesidad o en base al consentimiento de la víctima, estamos ante una creencia de que se está actuando conforme a la ley. ¿Puede tal persona sólo ser eximida del castigo si como consecuencia del error actúa sin mens rea? ¿Sería justo condenar al acusado a pesar de tal error? Parece ser claro de éste y de otros casos y está aceptado generalmente en la doctrina actual, que el error tal y como anteriormente se ha expuesto no puede aplicarse sin excepciones. Esto es todavía más evidente en Derecho penal internacional al contemplarse los tipos penales de forma más vaga (artículo 5-9, del Estatuto de Roma) ${ }^{144}$. Asi parece de que el ICC tendrá que emplear principios generales de la ley nacional (artículo 21 (1) (c)), porque el artículo 32 no contempla todos los casos posibles.

\footnotetext{
${ }^{140}$ Pero véase FLETCHER, (1998) supra nota 2, págs. 146-167 quien distingue entre seis tipos de errores y muestra que el MPC, supra nota 28 , falta por reconocer aquellos no comprendidos en el criterio del elemento mental, en especial errores sobre normas de justificación ("Erlaubnisirrtum") ○ excusa ("direkter" ○ "indirekter Verbotsirrtum"). Para un análisis extenso de la doctrina alemana, véase por ejemplo ROXIN, supra nota $9, \S 12$ II, 21; Kristian KÜHL, Strafrecht. Allgemeiner Teil, $2^{\text {nd }}$ ed. 1997, pág. 13. Véanse también las acertadas observaciones críticas de WISE, supra nota 7, en 54-55.

${ }^{141}$ Erdemovic dijo: "Vuestro honor - Tuve que hacerlo. Si hubiera rehusado habría muerto con las víctimas. Al rehusar me dirían: 'Si lo sientes por ellos, levántate, alíneate con ellos y te mataremos también.' No lo siento tanto por mí como por mi familia, mi esposa y mi hijo que entonces contaba tan sólo nueve meses de edad, y no pude rehusar pues me habrian matado". (Prosecutor v. Erdemovic, IT-96-22-T, Nov. 29, 1996, para. 10; traduc. del inglés).

${ }^{142}$ Véase supra nota 135

143 "Duress" es una causal de exculpación, véase supra nota 132 y texto principal.

${ }^{144}$ Véase recientemente también Christiane NILL-THEOBALD, supra nota 134, en 347-8.
} 
La previsión relativa a las órdenes superiores, contemplada en el artículo 33, fue una de las previsiones más controvertidas de la Parte III. ${ }^{145}$ La delegación de los Estados Unidos asistida por el profesor Theodor Meron, intentó convencer a las otras delegaciones en una reunión informal para que la conducta acorde con la orden del superior fuera reconocida como una defensa propia en Derecho internacional. Esta posición se fundamentó en una referencia a la actual doctrina militar de los Estados Unidos y en una declaración de Meron que situó a Nuremberg como precedente dentro de un contexto histórico. La posición de los Estados Unidos fue especialmente criticada por el Reino Unido, Nueva Zelanda y Alemania, que argumentaron que las órdenes superiores per se no pueden ser consideradas como defensa, como un subordinado puede, en un determinado caso, invocar otras defensas, tales como "duress" y error de hecho o legal. La previsión adoptada es una fórmula de compromiso entre estas dos posiciones. Se afirma el principio de que las órdenes del superior no son una defensa, aunque puede invocarse excepcionalmente en casos de crímenes de guerra bajo estrictas y limitadas condiciones. La previsión sigue el "principio de ilegalidad manifiesta"146 mientras que las actuales tendencias en Derecho internacional se decantan mejor por el "principio mens rea"147, rechazando considerar las órdenes del superior como argumento defensivo per $s e^{148}$. Mientras las más antiguas doctrinas están hoy rechazadas de plano ${ }^{149}$, existe todavía una interesante controversia entre los

145 "Artículo 33 Órdenes superiores y disposiciones legales

1. Quien hubiere cometido un crimen de la competencia de la Corte en cumplimiento de una orden emitida por un gobierno o un superior, sea militar o civil, no será eximido de responsabilidad penal a menos que:

a) Estuviere obligado por ley a obedecer órdenes emitidas por el gobierno o el superior de que se trate;

b) No supiera que la orden era ilicita; y

c) La orden no fuera manifiestamente ilícita.

2. A los efectos del presente artículo, se entenderá que las órdenes de cometer genocidio o crímenes de lesa humanidad son manifiestamente ilicitas."

${ }^{146}$ Véase GREENSPAN. The Modern Law of Land Warfare 440-2, 490-496 (1959); L.C. GREEN, Superior Orders in National and International Law 237-8, 243 y sigs. (1976); véase recientemente MEZZETI, supra nota 135, en 155-7, quien, sin embargo, parece ignorar el "principio mens rea".

147 Véase DINSTEIN, supra nota 134, págs. 87-90, en 88:"... el hecho de obediencia a órdenes constituye no un argumento defensivo per se sino sólo un elemento de hecho que puede ser tenido en cuenta en conjunción con las otras circunstancias del caso dado en el marco de una defensa basada en una falta de mens rea, que es, error de ley o hecho o coacción."

${ }^{148}$ Véase más recientemente el Proyecto de Código de 1996, supra nota 20, artículo 5. Véase para un análisis del Derecho positivo y de la jurisprudencia: NILL-THEOBALD, supra nota 134, en 73-107; véase también A.P.V. ROGERS, supra nota 66, 143-148; WISE, supra nota 7, en 58; AMBOS, "Zur strafbefreienden Wirkung des "Handelns auf Befehl" aus deutscher und völkerstrafrechtlicher Sicht", Juristische Rundschau 221-226, 223 y sigs. (1998); en castellano en La Ley - Revista Juridica Española de Doctrina, Jurisprudencia y Bibliografía 20 (8.12.1999), 1-5

${ }^{149}$ Para la doctrina de "respondeat superior" por un lado y la "doctrina de absolute liability", por otro, véase: NILL. THEOBALD, supra nota 134, en 69-72; también ESER, supra nota 133, págs. 204, 206-8. 
dos principios mencionados. Ciertamente ambos se basan en argumentos convincentes (aunque la diferencia en la práctica es difícil de establecer) ${ }^{150}$.

De esta controversia se sigue que hay casos en los que una actuación subordinada en base a las órdenes de los superiores no merece castigo. El ejemplo más reciente es el caso de Erdemovic. La única cuestión consiste en saber si, en tales casos, una defensa (per se) de las órdenes superiores es o no necesaria. Se argumenta que la orden es sólo un elemento de hecho, de otra forma de defensa denominada "duress" o error de hecho o de derecho, y que esta defensa puede ayudar al subordinado. Esto parece ser correcto a partir de la comparación de los valores legales en cuestión. EI concepto de orden superior proviene de la necesidad de mantener la disciplina así como el orden en las organizaciones jerárquicamente estructuradas. Pero tales objetivos, ceden ante valores legales protegidos por el Derecho penal internacional y codificados en el Estatuto de Roma, así como por la especial gravedad de los crímenes. De hecho, el artículo 33 (2) asume esta posición respecto al genocidio y crímenes contra la Humanidad, porque las órdenes de cometer tales delitos están consideradas per se manifiestamente ilegales. Sin embargo, esto no es suficiente. La frase correcta fue propuesta por el profesor Edward Wise: "Una persona no quedará exenta de responsabilidad criminal por el simple hecho de estar siguiendo órdenes de ... un superior ..."151.

Aparte de otros argumentos defensivos establecidos en el Estatuto de Roma, el Tribunal puede considerar formas supralegales de exclusión de la responsabilidad criminal distintas de aquellas referidas en el artículo 31 (1) de acuerdo con las reglas de procedimiento y prueba, haciendo uso del principio de ley aplicable de acuerdo con el artículo 21 (artículo $31(3))^{152}$

\section{CONCLUSIÓN}

Este análisis preliminar de los principios generales del Estatuto de Roma, muestra que es más que necesario continuar con el desarrollo de un sistema suficientemente concreto y diferenciado de reglas de imputación en Derecho penal internacional. Un trabajo de este tipo tiene que partir de una base sólida de Derecho penal comparado, sin perder de vista el hecho de que los delitos internacionales no siguen los mismos patrones que los delitos nacionales. Las distintas formas de criminalidad nacional e internacional, pueden identificarse en el crimen transnacional

\footnotetext{
${ }^{150}$ Cf. ROGERS, supra nota 66 , en $146-8$.

${ }^{151}$ WISE, supra nota 7 , en 58 ,

${ }^{152}$ Véase también artículo 31 (1): " Sin perjuicio de las demás circunstancias..." (enfasis el autor).
} 
organizado, de modo que esto puede servir de base para desarrollar reglas que permitan seguir avanzando en la construcción del Derecho penal internacional. 